\title{
Review Article \\ Recent Studies on the Speciation and Determination of Mercury in Different Environmental Matrices Using Various Analytical Techniques
}

\author{
Lakshmi Narayana Suvarapu and Sung-Ok Baek \\ Department of Environmental Engineering, Yeungnam University, Gyeongsan-Si 38541, Republic of Korea \\ Correspondence should be addressed to Lakshmi Narayana Suvarapu; suvarapu@gmail.com
}

Received 26 June 2017; Accepted 26 October 2017; Published 20 November 2017

Academic Editor: Günther K. Bonn

Copyright (C) 2017 Lakshmi Narayana Suvarapu and Sung-Ok Baek. This is an open access article distributed under the Creative Commons Attribution License, which permits unrestricted use, distribution, and reproduction in any medium, provided the original work is properly cited.

\begin{abstract}
This paper reviews the current research on the speciation and determination of mercury by various analytical techniques, including the atomic absorption spectrometry (AAS), voltammetry, inductively coupled plasma optical emission spectrometry (ICP-OES), ICP-mass spectrometry (MS), atomic fluorescence spectrometry (AFS), spectrophotometry, spectrofluorometry, and high performance liquid chromatography (HPLC). Approximately 96 research papers on the speciation and determination of mercury by various analytical instruments published in international journals since 2015 were reviewed. All analytical parameters, including the limits of detection, linearity range, quality assurance and control, applicability, and interfering ions, evaluated in the reviewed articles were tabulated. In this review, we found a lack of information in speciation studies of mercury in recent years. Another important conclusion from this review was that there were few studies regarding the concentration of mercury in the atmosphere.
\end{abstract}

\section{Introduction}

Mercury is the only metal that exists in a liquid state among the elements in our modern periodic table. Determination and speciation studies of mercury attract researchers because of the toxicity of mercury to humans, as well as to other animals in the food web. The difference between the toxicity of mercury and that of other metals is that mercury easily accumulates in organisms. A few studies have reported bioaccumulation of mercury in various aquatic animals, such as fishes, pelagic seabirds, and earthworms [1-9].

This section describes the sources and fate of mercury in the environment and its toxicity.

1.1. Sources and Fate of Mercury in the Environment. Mercury can enter the environment from natural and/or anthropogenic sources. Natural sources of mercury include volcanoes, forest fires, cinnabar (ore), and fossil fuels, such as coal and petroleum. Anthropogenic sources are numerous; a large number of human activities are responsible for mercury deposition in the environment. Anthropogenic sources of mercury are landfills, dental preparations, and combustion processes, such as coal-fired power generation, medicinal waste incinerators, and municipal waste combustion. Manufacture of metals, alkali, and cement also releases mercury into the environment [10]. Anthropogenic sources are related to human activities in contaminated locations. This section describes the sources of mercury in the environment, reported from various parts of the world. Zhuang and Gao [11] reported higher concentrations of mercury in riverine sediments than in marine sediments and concluded that river transportation was the main source of mercury in southwestern Laizhou Bay, China. Kwon et al. [12] found that watershed runoff was the primary route of mercury transfer between lakes and forests.

$\mathrm{Xu}$ et al. [13] revealed that mercury concentration in soil has recently increased 3-10 times because of the combustion of fossil fuels combined with long-range atmospheric 
transportation processes. Shamsipur et al. [14] and Rajabi et al. [15] reported the determination of mercury in water samples using spectrometric and electrochemical techniques, respectively. Han et al. [16] found lower concentrations of wet-deposited mercury in forest areas of South Korea during summer because of precipitation. The concentration of mercury in the atmosphere was influenced by the seasons. In the atmosphere, coal combustion was the major source of gaseous elemental mercury, but traffic emissions contributed particulate mercury. Domestic pollutants are major sources of reactive gaseous mercury [17].

\subsection{Toxicity and Health Implications of Mercury and Its Differ-} ent Species. Researchers determine the concentration of mercury in environmental segments because of its toxic nature. Numerous journal articles have been published regarding the toxicity of mercury and its different forms. Yoshida et al. [18] reported on its neurobehavioral toxicity in mice exposed to low-level mercury vapor and methylmercury. Bucio et al. [19] studied the toxicity of mercury in a human hepatic cell line (WRL-68 cells). Results of this study indicated that higher doses of mercury cause cytotoxic effects with the release of lactate dehydrogenase from cells. Mercury exposure can cause neurodegeneration with oxidative stress in mitochondria [20]. Occupational exposure to mercury in workers of a fluorescent lamp factory in Egypt resulted in symptoms including emotional ability, memory changes, neuromuscular changes, and performance deficits in tests of cognitive function [21]. Mercury(II) and methylmercury toxicity can inhibit the human thioredoxin system. Mercury inhibition is selective for the thioredoxin system; mercury binds with selenol-thiol in the active sites of thioredoxin reductase [22]. Methylmercury reacts with the sulfhydryl groups throughout the human body and influences the functions of cellular and subcellular structures. Mercury toxicity in various forms can cause thyroid dysfunction because of the inhibition of $5^{\prime}$ deiodonases, spermatogenesis because of accumulation in the testicles, and atrophy and capillary damage in thigh muscles [23]. Tonazzi et al. found a correlation between mitochondrial carnitine-acylcarnitine transporter inactivation and mercury toxicity in animals [24]. Mercury toxicity in humans can cause numerous neurological or psychiatric disorders not limited to autism spectrum disorders, Alzheimer's disease, Parkinson's disease, epilepsy, depression, and tremor. In rats, mercury(II) toxicity affects the central neurons and leads to cytoskeleton instability [25]. Exposure to organic forms of mercury, such as ethylmercury or methylmercury, can cause neurotoxic effects in developing mammals. Ethylmercury exposure in humans occurs because of immunization with thimerosal-containing vaccines [26]. The toxicity of mercury not only is limited to neurological effects in humans, but also causes vascular effects, such as increased oxidative stress and inflammation, thrombosis, endothelial dysfunction, dyslipidemia, and immune and mitochondrial dysfunctions [27]. Overall, the toxicity of mercury in animals and humans affects the cardiovascular, hematological, pulmonary, renal, immunological, neurological, endocrine, reproductive, and embryonic systems [28].
Plants are exposed to mercury compounds through the administration of antifungal agents. The toxicity of mercury affects seed germination, growth, and development in higher plants. It also causes the breakdown of photosynthesis by affecting chlorophyll and magnesium molecules [29]. Mercury toxicity induces oxidative stress in growing cucumber seedlings and results in plant injury [30]. Mercury that has accumulated in different forms within plants can cause phytotoxicity and impair numerous metabolic processes, including nutrient uptake, water status, and photosynthesis [31].

In this present study, we reviewed speciation and determination studies of mercury in different environmental samples using various analytical techniques, including the atomic absorption spectrometry (AAS), voltammetry, inductively coupled plasma optical emission spectrometry (ICP-OES), ICP-mass spectrometry (MS), atomic fluorescence spectrometry (AFS), spectrophotometry, spectrofluorometry, and high performance liquid chromatography (HPLC). Over 96 research papers published since 2015 in reputable international journals were reviewed. This review clearly summarizes the current research on speciation and determination studies of mercury from locations worldwide.

\section{Reviews of the Determination of Mercury}

The toxic nature of mercury and its different species encourage researchers to determine their concentrations in different environmental samples. Recently, a number of reviews were published concerning the determination of mercury, which described various factors regarding the concentrations of mercury in the environment. This section summarizes recent reviews of the determination of mercury.

Hanna et al. [32] reviewed the concentrations of mercury in freshwater fishes of Africa. They reviewed 30 identified studies in which the authors collected $407 \mathrm{Hg}$ concentrations from 166 fish species, 10 types of invertebrates, and various plankton species from 12 countries in Africa. The authors concluded there was a lack of data regarding $\mathrm{Hg}$ concentrations in African countries. However, based on available data, $\mathrm{Hg}$ concentrations were lower than that of the World Health Organization (WHO) recommendations for commercially available fishes in Africa. Ferreira et al. [33] reviewed analytical strategies of sample preparation for the determination of mercury in food samples using a cold vapor atomic absorption spectrometry (CV-AAS), cold vapor atomic fluorescence spectrometry (CV-AFS), inductively couple plasma mass spectrometry (ICP-MS), voltammetry, and neutron activation analysis. Based on the reviewed papers, they concluded that the determination of mercury and its species in food samples with CV-AFS or CVAAS was simpler and less expensive than other methods.

Colorimetric and visual assay determination of $\mathrm{Hg}(\mathrm{II})$ based on gold nanoparticles, fluorescent gold nanoparticles, gold nanorods, gold nanoflowers, and gold nanostars was reviewed by Chansuvarn et al. [34]. They reported that gold nanoparticles were the most promising luminescent nanomaterials for the detection of $\mathrm{Hg}$ (II) because of high 
selectivity and ultrasensitivity. Regarding analytical instruments, the UV-visible spectrophotometer was cost-effective for limited-budget laboratories for real-time monitoring of $\mathrm{Hg}$ (II) in environmental samples. Ariya et al. [35] reviewed physiochemical and biogeochemical transformation of mercury in the atmosphere and at atmospheric interfaces. The authors described the analytical methodology for speciation of mercury in the atmosphere, exchange of $\mathrm{Hg}$ between the atmosphere and aquatic interfaces, and exchange of $\mathrm{Hg}$ between the atmosphere and terrestrial environments. Shrivastava et al. [36] reviewed $\mathrm{Hg}$ detoxification mechanisms in plants. The authors found that $\mathrm{Hg}$ had harmful toxic effects on the molecular and physiobiochemical behavior of plants. Another important conclusion of this study was that most research was conducted on seed germination and shoot, root, and leaf morphology. Duarte et al. [37] reviewed the utility of disposable sensors for the detection of lead(II), cadmium(II), and mercury(II) in the environment. The paper describes analytical performance and the effect of certain factors, such as immobilization procedures and surface modification, on the analytical characteristics of the sensors. The authors found that disposable sensors used for single measurements of lead(II), cadmium(II), and mercury (II) in environmental samples had adequate intersensor reproducibility, sensitivity, and selectivity and very low detection limits. They concluded that the modified carbon paste electrode provided better determination of $\mathrm{Hg}(\mathrm{II})$ and $\mathrm{As}(\mathrm{III})$, because of superior deposition with linear and improved responses under the set of studied conditions. The authors stated that the disadvantages of using macroelectrodes included their expense and that they suffered from surface fouling even though they provided better sensitivity and selectivity for the determination of $\mathrm{Hg}(\mathrm{II})$ and $\mathrm{As}$ (III).

Jagtap and Maher [38] reviewed the measurement of mercury species in sediments and soils by HPLC coupled with ICP-MS. The authors recommended the extraction of $\mathrm{Hg}$ species for determination by distillation or use of 2mercaptoethanol. They also recommended usage of C8 as the stationary phase and 2-mercaptoethanol as the mobile phase in HPLC for accurate quantification of methyl mercury in presence of large amounts of $\mathrm{Hg}$ (II). Gustin et al. [39] reviewed the measurement and modeling of mercury in the atmosphere. These authors reported that mercury in the atmosphere can exist in three different forms, gaseous elemental mercury (GEM), gaseous oxidized mercury (GOM), and particulate bound mercury (PBM). Among these forms, there was relative confidence in GEM measurements only, whereas the remaining two forms were less understood. These authors concluded that only through the comparison of multiple calibrated measurements could the results be determined accurately. McLagan et al. [40] reviewed passive air sampling of GEM in the atmosphere. They found that the performance of the passive air sampling method must be validated against active air monitoring systems with satisfactory precision and accuracy. Jackson and Punshon [41] reviewed recent advances in the measurements of arsenic, cadmium, and mercury in rice and other food materials. They described the challenges, state-of-the-art methods, and usage of spatially resolved techniques for arsenic and mercury within rice grains. However, this review focused mainly on the determination and speciation studies of arsenic rather than mercury. Duan and Zhan [42] reviewed recent use of nanomaterials-based (noble metal nanoparticles, fluorescent metal nanoclusters, semiconductors quantum dots, and carbon nanodots) optical sensors for $\mathrm{Hg}$ (II) detection. They concluded that the advantages of using nanomaterials for $\mathrm{Hg}$ (II) detection and removal included higher sensitivity and selectivity, simpler and more rapid procedures, and lower cost than that of conventional methods. Sun et al. [43] reviewed the recent progress in detection of $\mathrm{Hg}$ using surface enhanced Raman spectroscopy (SERS). They stated that substantial enhancement in detectable Raman signals coupled with a unique nanoparticle-based approach made SERS a powerful tool for the detection of $\mathrm{Hg}(\mathrm{II})$. Suvarapu and Baek [44] reviewed the speciation and determination of mercury using various analytical techniques. They discussed research papers published during 2013-2014 on these topics.

\section{Discussion}

In recent years, a large number of research articles were published regarding the determination and speciation of mercury using various analytical techniques. We have divided this section into four parts based on the analytical techniques used in the determination of type and levels of mercury. They are (i) spectrometric techniques (AAS, AFS, ICP-OES, MS, spectrophotometry, and spectrofluorometry), (ii) electrochemical techniques (voltammetry and potentiometry), and (iii) miscellaneous techniques.

The determination and speciation of mercury using spectrometric techniques, such as AAS, AFS, ICP-OES, ICP-MS, spectrophotometry, and spectrofluorometry are presented in Table 1. Table 2 represents the determination of mercury using electrochemical techniques, and Table 3 represents the determination of mercury using miscellaneous techniques. In these tables, we have incorporated all the analytical variables of merit, such as limits of detection, linearity range, quality control and assurance, applicability (analyzed samples), and interference reported in the determination of mercury.

Regarding the usage of analytical techniques in the determination studies of mercury, as presented in Figure 1,52.00\% used spectrometric techniques, such as AAS, AFS, ICPOES, ICP-MS, spectrometry, and spectrofluorometry, $30.00 \%$ used electrochemical techniques, such as a voltammetry and potentiometry, and $15.00 \%$ used miscellaneous techniques.

The analytical variables of merit, such as limits of detection and linearity, quality control and assurance studies, applicability to natural samples, and interference, are indicative of the validity of the method. Detection limit indicates the lowest level of analyte that can be detected using the method. A few studies [45-51] reported lowest levels down to picograms of mercury. Methods used in these studies can be considered highly sensitive because of their low detection limits. The lower detection limits were primarily obtained with ICP-MS and CV-AFS. On the other hand, spectrophotometers and spectrofluorometers can provide reasonable sensitivity, and they are inexpensive compared to ICP instruments. Linearity describes the range within which 


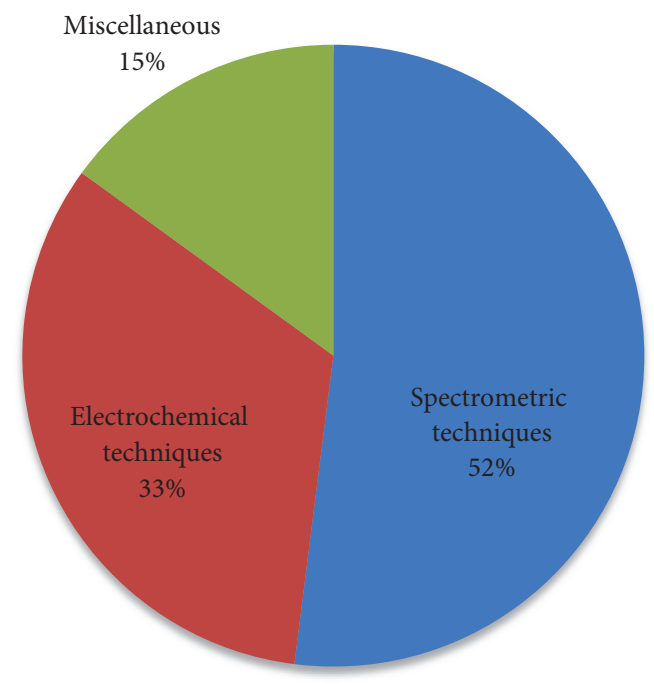

FIgURE 1: Determination and speciation of mercury using various analytical techniques.

the method can determine analyte concentrations. Most of the electrochemical methods and spectrophotometry and spectrofluorometry methods determined the linearity range of analyte concentrations.

Two very important analytical parameters, in the determination of mercury, are quality assurance (QA) and quality control (QC). The validity and reliability of the data produced by the researchers depend on the quantification of these variables. Quality assurance studies can be performed by testing the accuracy of the data obtained against standard reference materials (SRMs) provided by the National Institute of Standards and Technology (NIST, USA) or certified reference materials (CRMs) provided by various reputable institutes or organizations. Quality control can be determined by measuring the precision of the data (repeatability and sensitivity) obtained by each method. The precision of the data can be obtained in many ways, such as the analysis of replicates, interlab comparison of data, and relative standard deviation (RSD) of blank or standard material analysis [52]. Regarding QA, in the reviewed papers, a few [45, 53-57] reported the analysis of SRMs to compare with the results of their methods. The results obtained with the measuring of SRMs give validity to the obtained data. The other alternative to measure the accuracy of the data is the analysis of CRMs. A large number of studies [45, 47, 55, 56, 58-67] reported the analysis of CRMs to validate their data. Regarding QC, most of the studies reported the RSD values for replicate sample analysis and/or standard materials analysis. Overall, most researchers were aware of the quality of their data, whereas a few $[46,51,68-87]$ did not report any QA or QC values, which negatively affected the reliability of their data.

The validity of analytical methods can be enhanced by applicability to natural samples. Regarding the analysis of natural samples, most of the reviewed papers analyzed water samples, such as those from rivers, lakes, seas, groundwater, and spiked water and wastewater. Following water samples, the most frequently analyzed material for mercury was seafood samples, such as fish, shrimp, and seaweed. A few studies reported the determination of mercury in various environmental samples, such as petroleum hydrocarbons [88], human hair $[89,90]$, phosphate fertilizers [53], glycerin [91], sediments [55, 92, 93], cosmetics [94], living cells [66, 95], and tobacco [67]. However, a few methods [74, 81, 87, 96101] did not report their applicability to natural samples. We found that very few authors [46] determined mercury content in the atmosphere. Because of the difficulty in sampling and analysis, most authors did not address this issue.

Another important aspect of analytical parameters of the methods is interference. Interference of other ions in the determination of mercury levels is very important, particularly when those methods are applied to the analysis of natural samples. Natural samples are typically a complex of different ions; the selectivity of the method is very important in the determination of mercury in environmental samples. In this respect, electrochemical methods had a higher degree of selectivity and did not suffer from interference from other ions. Determination of the level of interference was not performed by a large number of authors [45-47, 53, $55,59,60,62,63,69,88,91,92,102-106]$ who determined mercury with spectrometric instruments. However, those using electrochemical instruments, spectrophotometers, or spectrofluorometers largely reported the level of interfering ion(s).

Toxicity of mercury depends upon its chemical form. For example, methylmercury is more toxic than inorganic mercury. Speciation studies revealed the exact toxicity of mercury in environmental samples. However, very few authors $[88,90,92,107]$ reported the speciation of mercury, and most authors determined the level of inorganic mercury. More than $90 \%$ of studies using electrochemical methods or spectrophotometry and spectrofluorometry techniques determined divalent inorganic mercury and did not report speciation. However, a few reported $[51,53,55,57,58,60-$ $62,66-68,85,86,93,102-106,108,109]$ total mercury content in various samples, which does not accurately predict toxicity based on its concentration.

\section{Conclusions}

The present study reviewed research articles published in recent years (2015-2016) involving determination and speciation of mercury using various analytical instruments. Approximately 100 research papers were reviewed and all the analytical parameters established in their studies were tabulated. Our study concluded that most of researchers used spectrometric instruments for the determination of mercury in different environmental samples. We addressed the quality of the data based on reported QA and QC data by the authors. Another important finding from this review was that most researchers measured inorganic mercury or total mercury, whereas only a few reported speciation of mercury. Speciation studies are very important in the accurate prediction of the toxicity of the mercury in the environment because mercury toxicity depends on its chemical form. Because of the difficulty in sampling and analysis, most researchers did not report the concentrations of mercury in the atmosphere. 


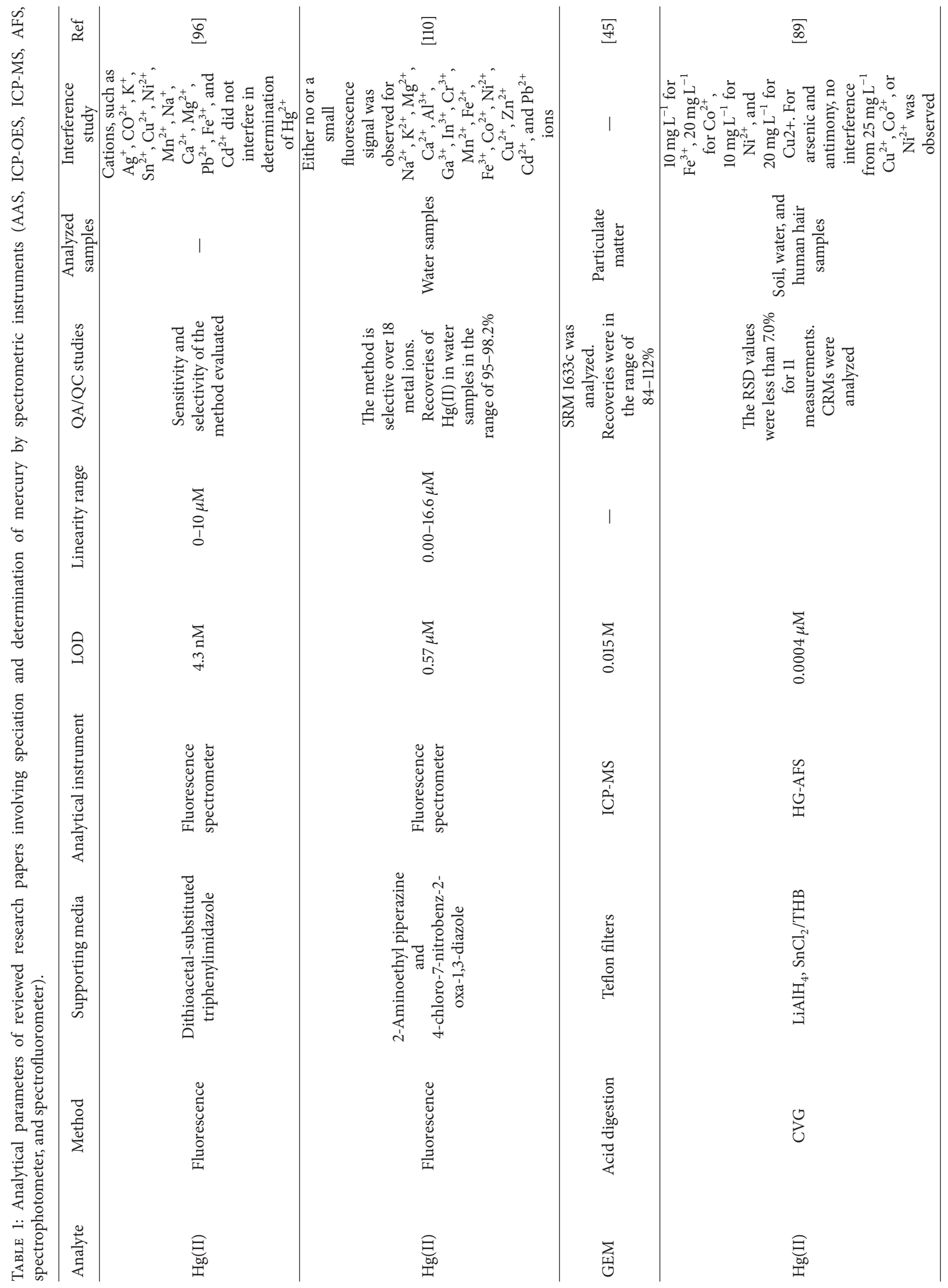




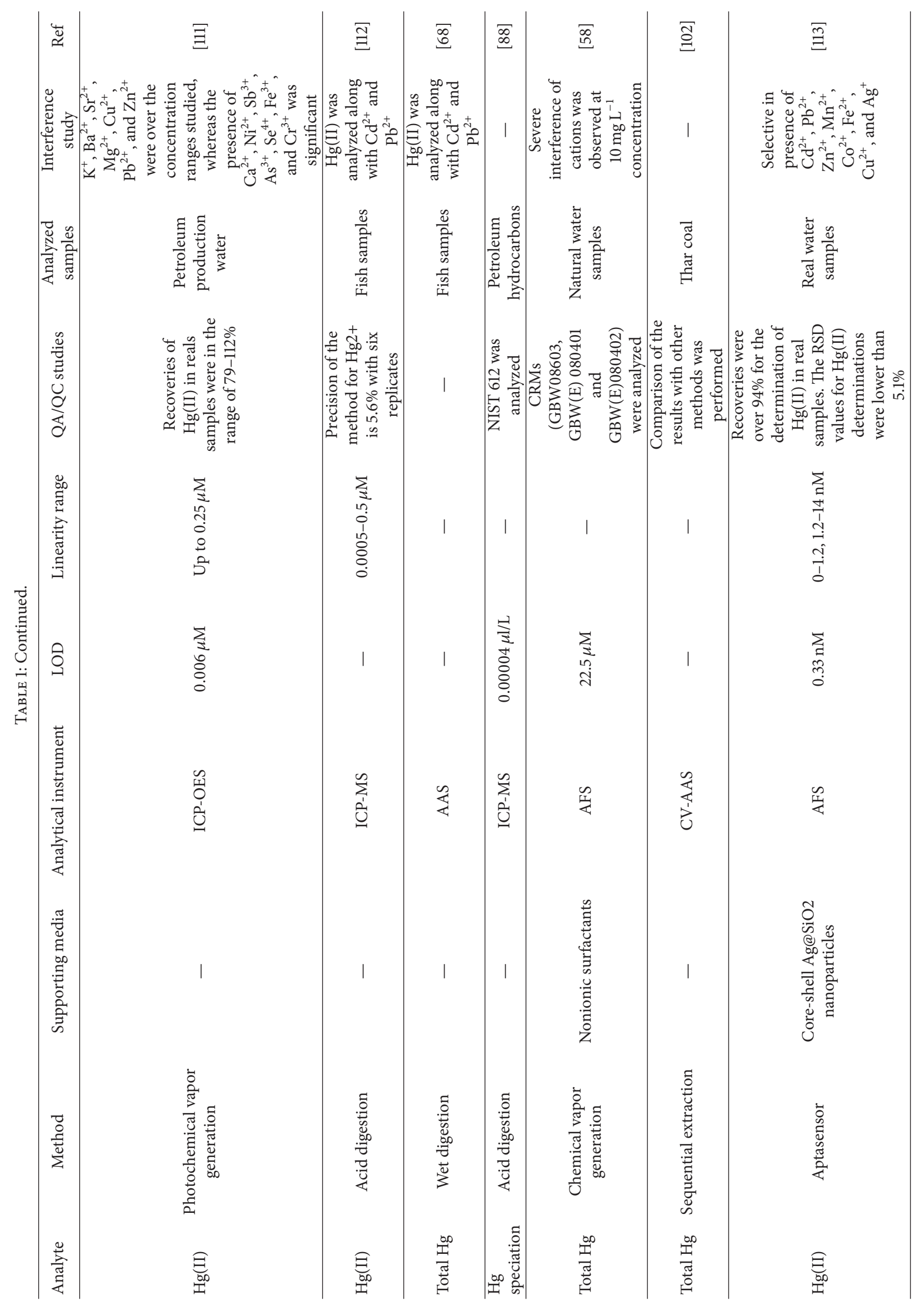




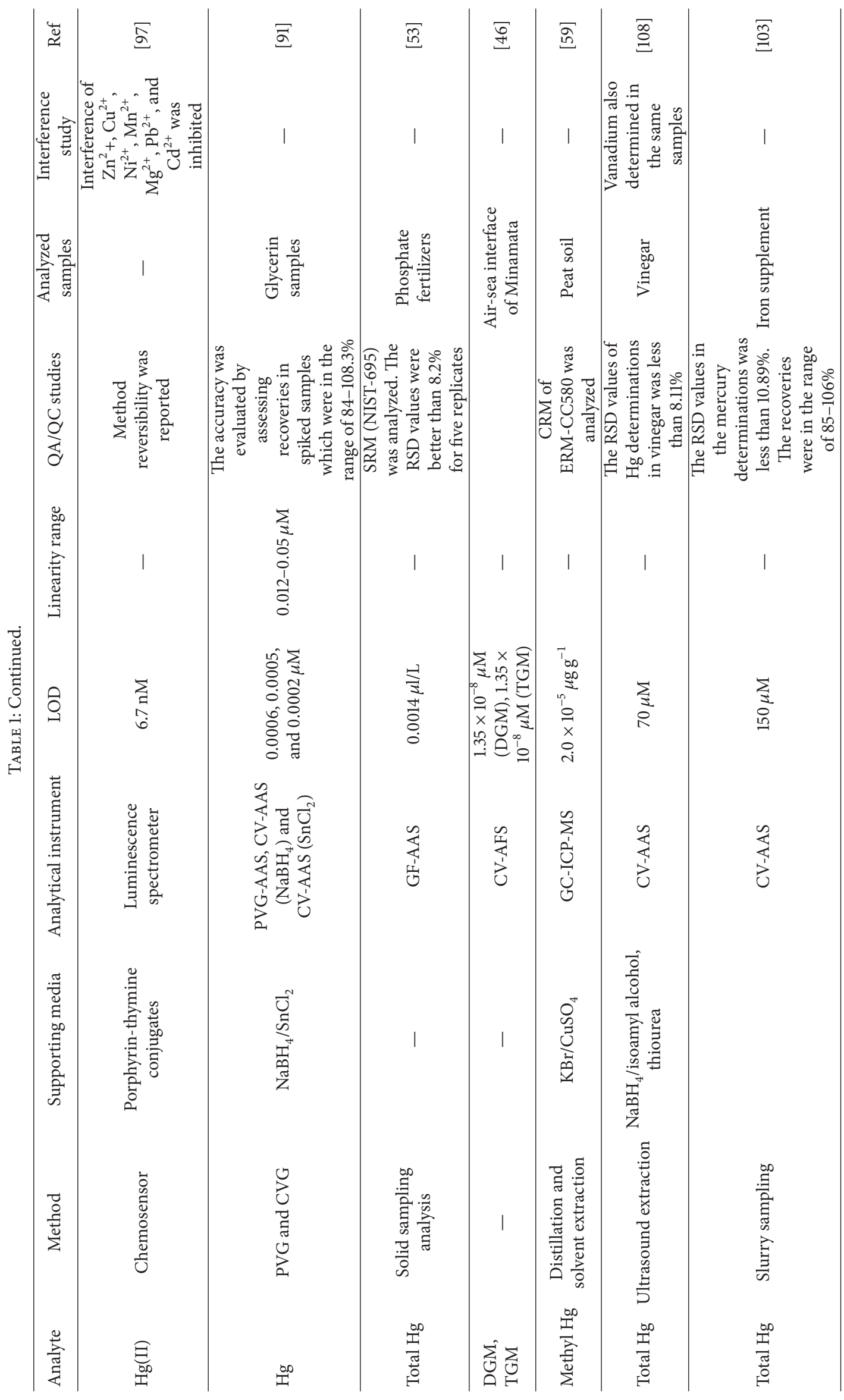




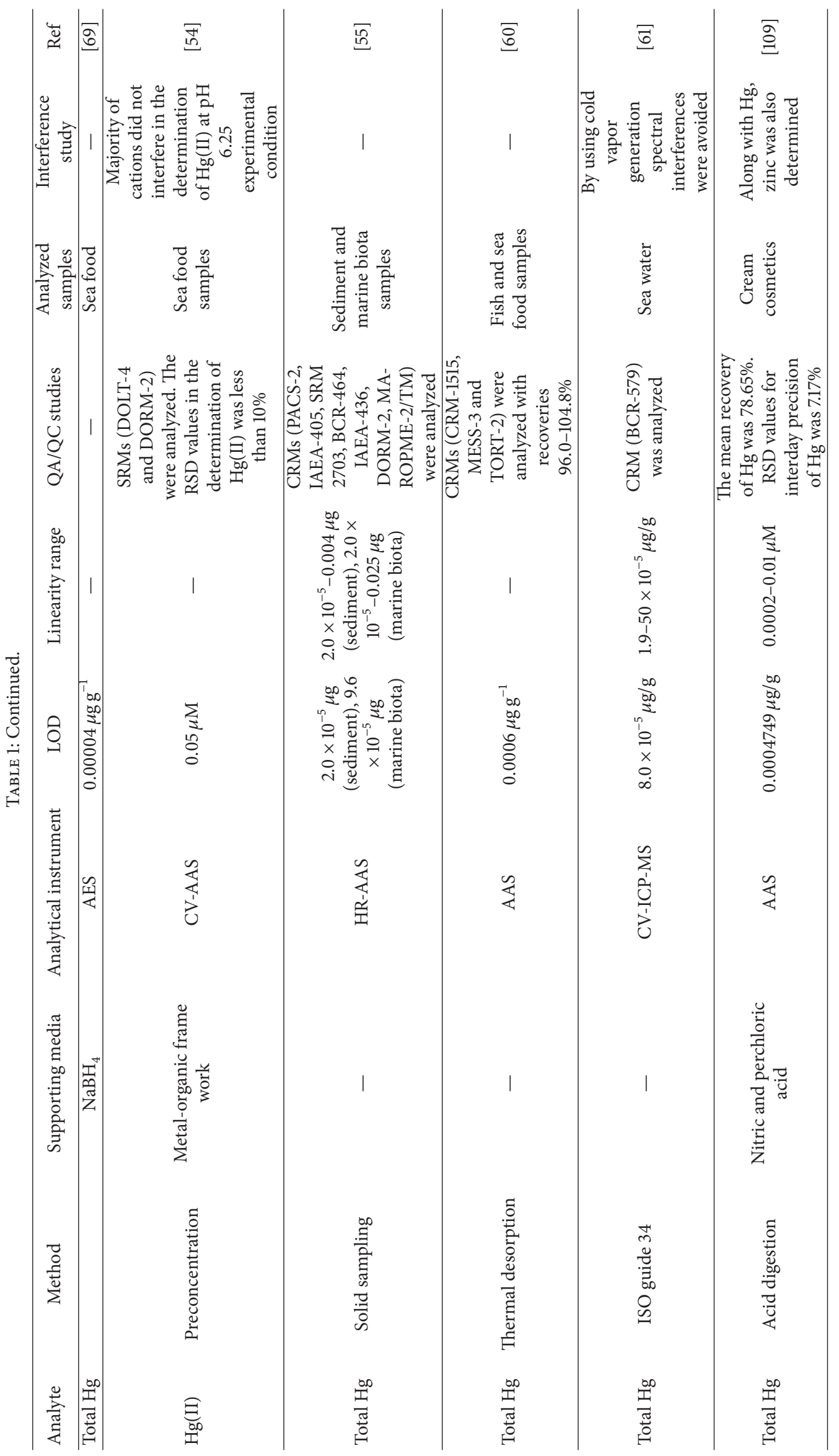




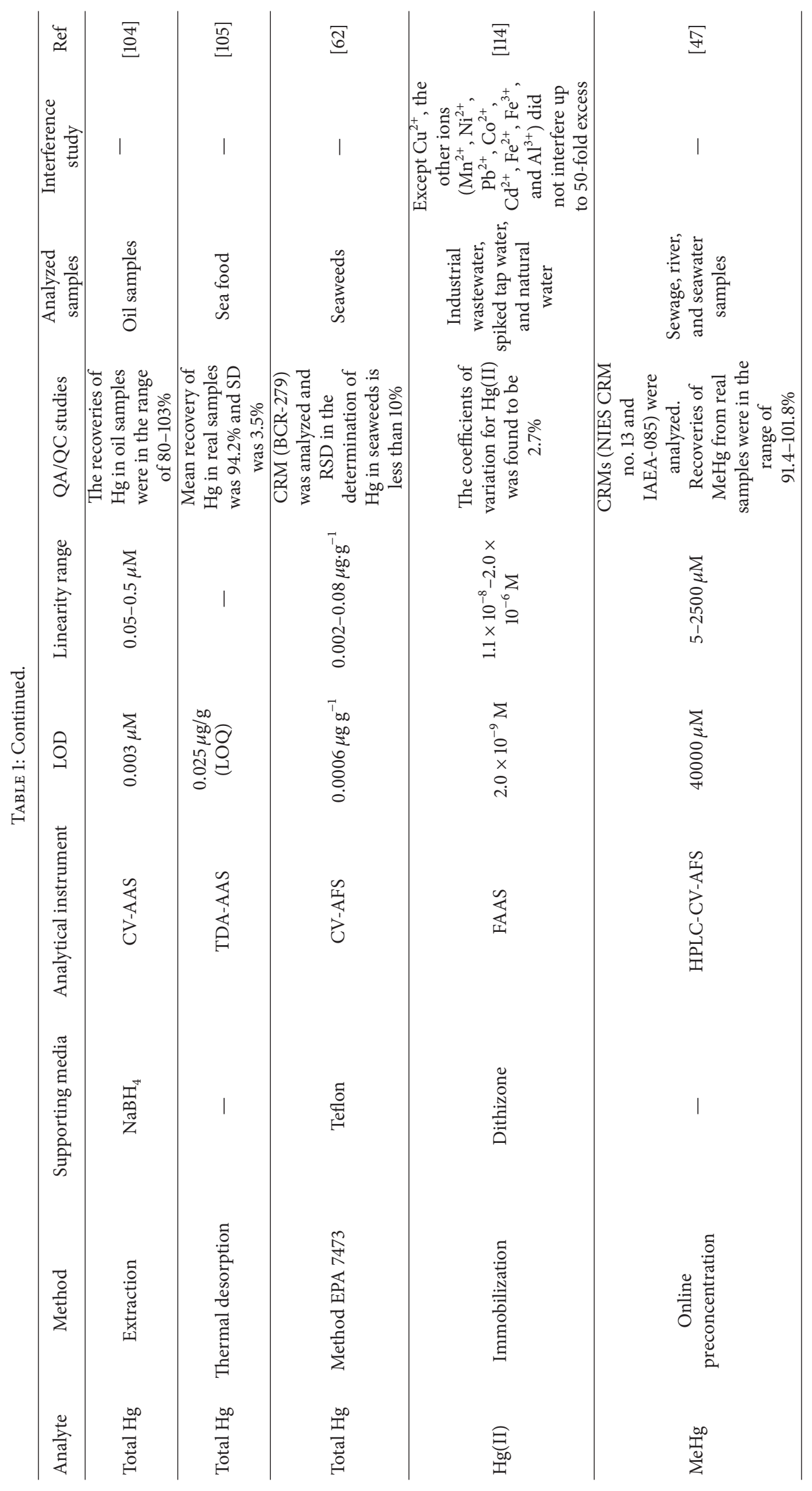




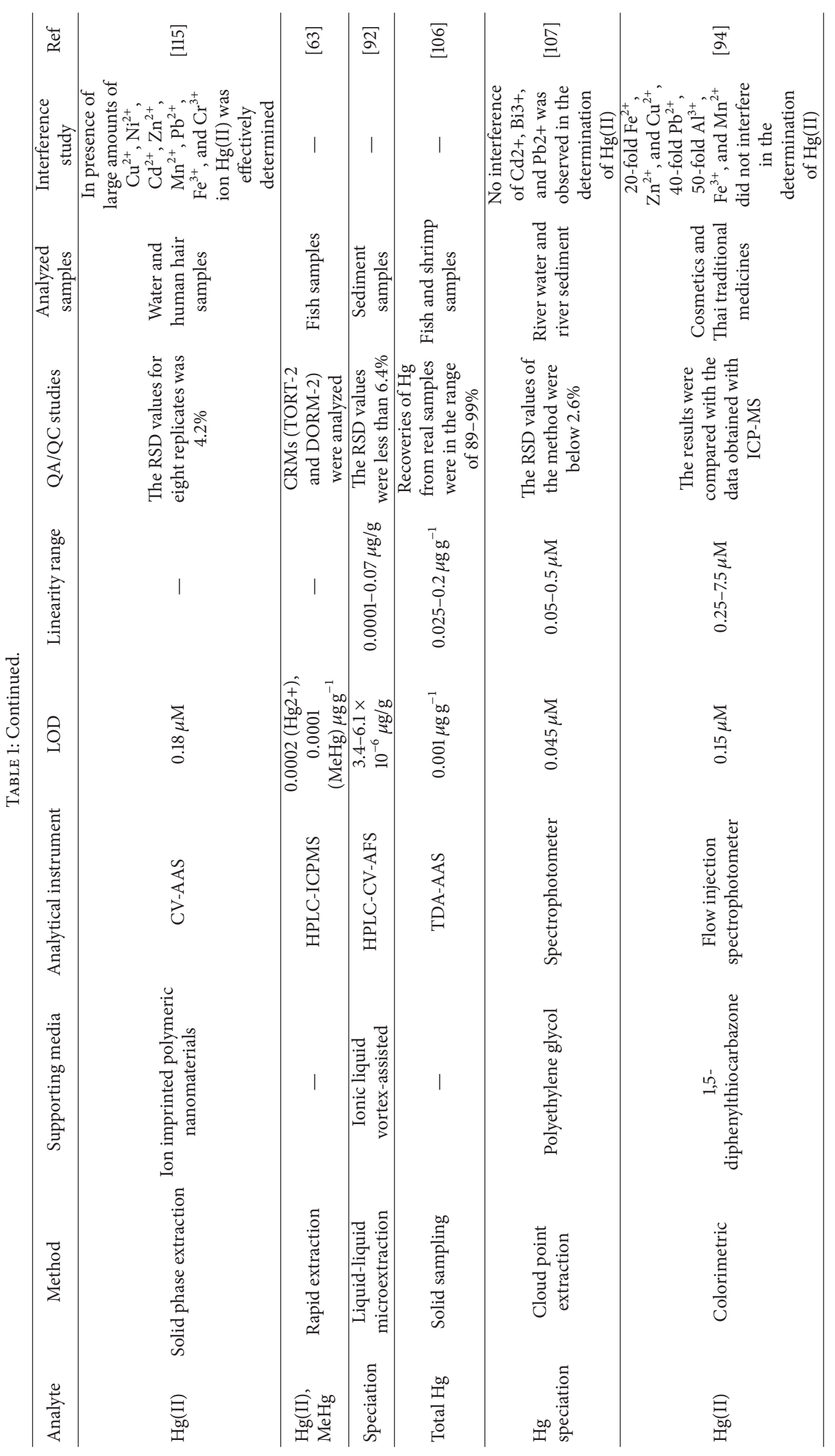




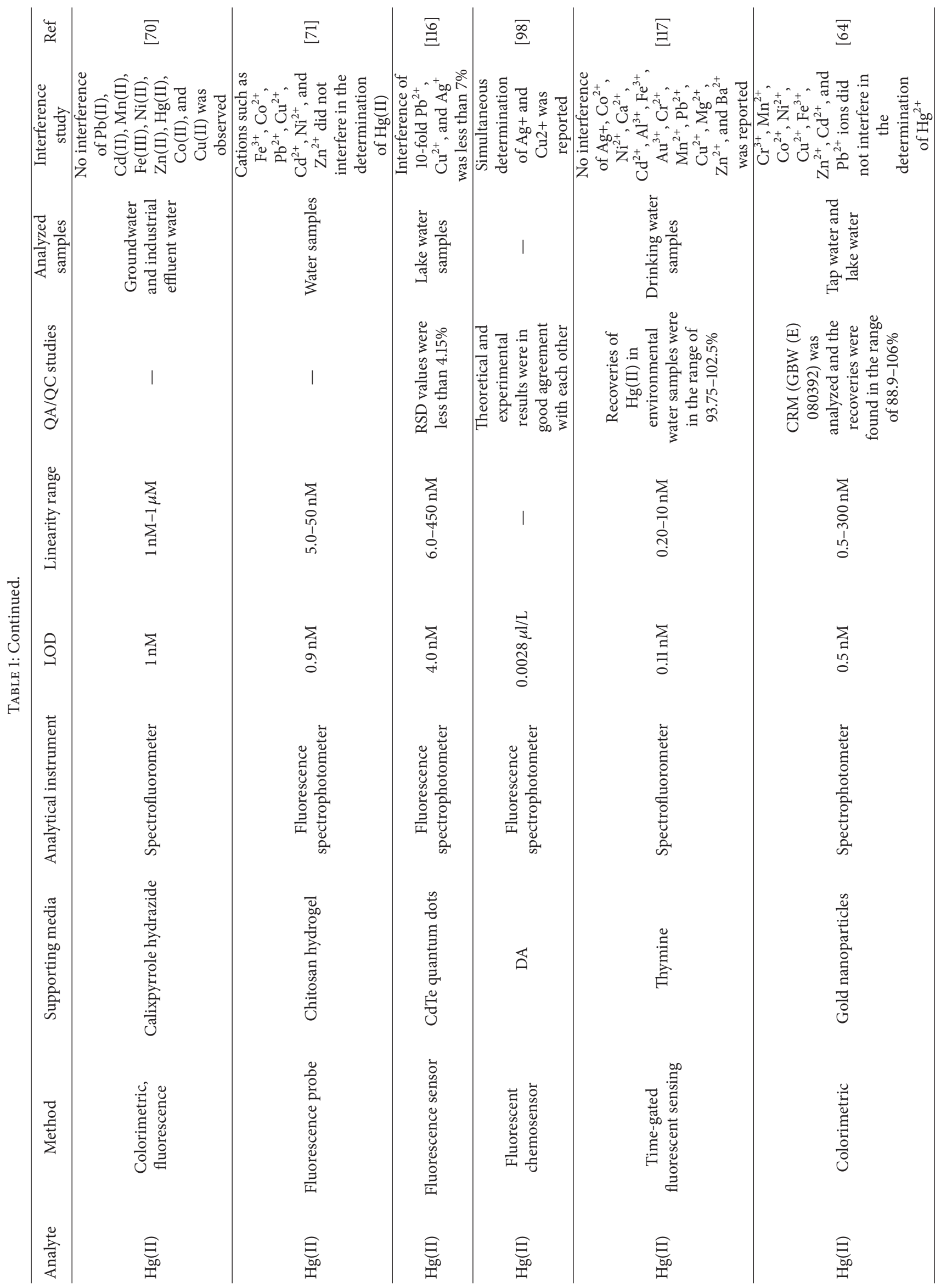




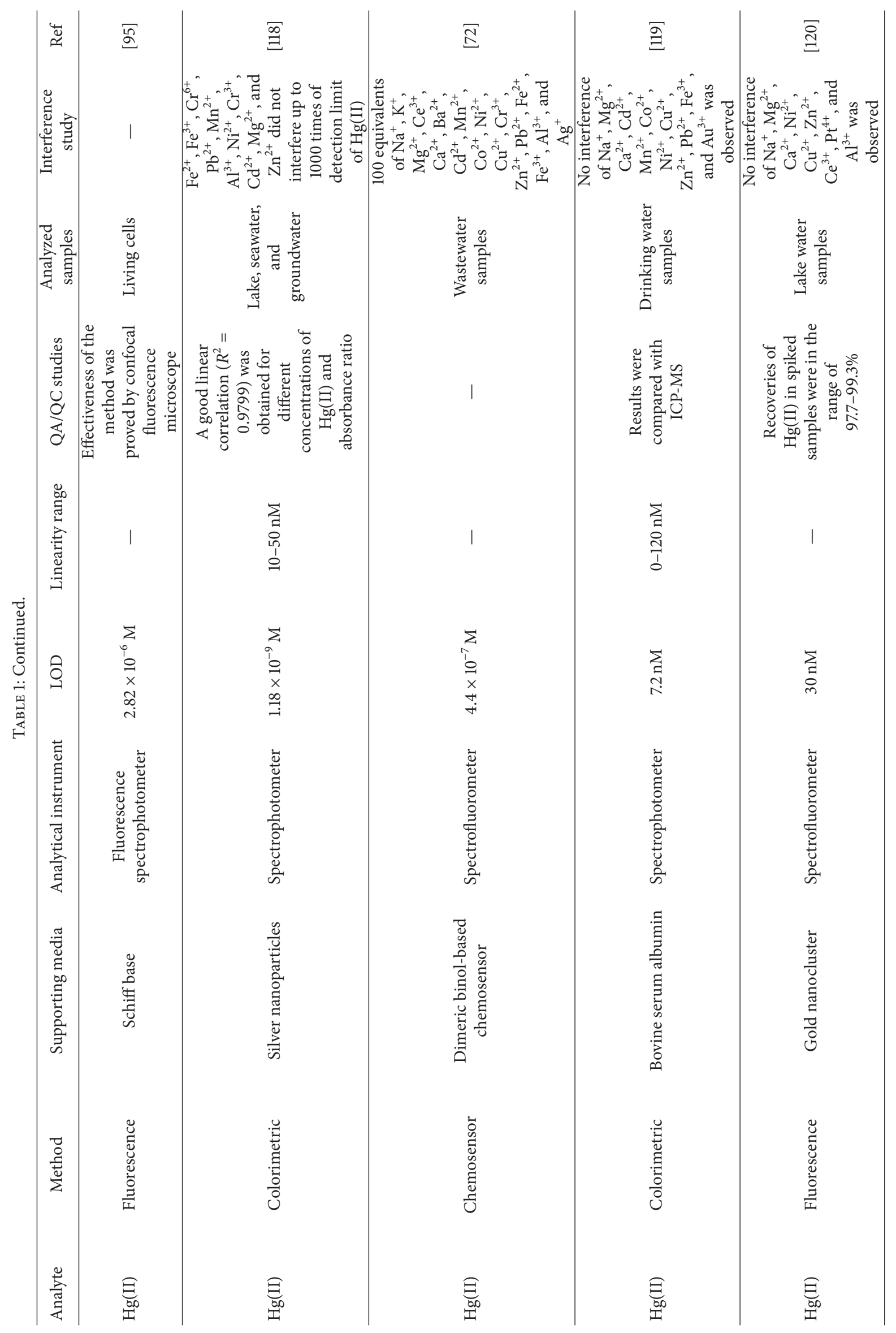




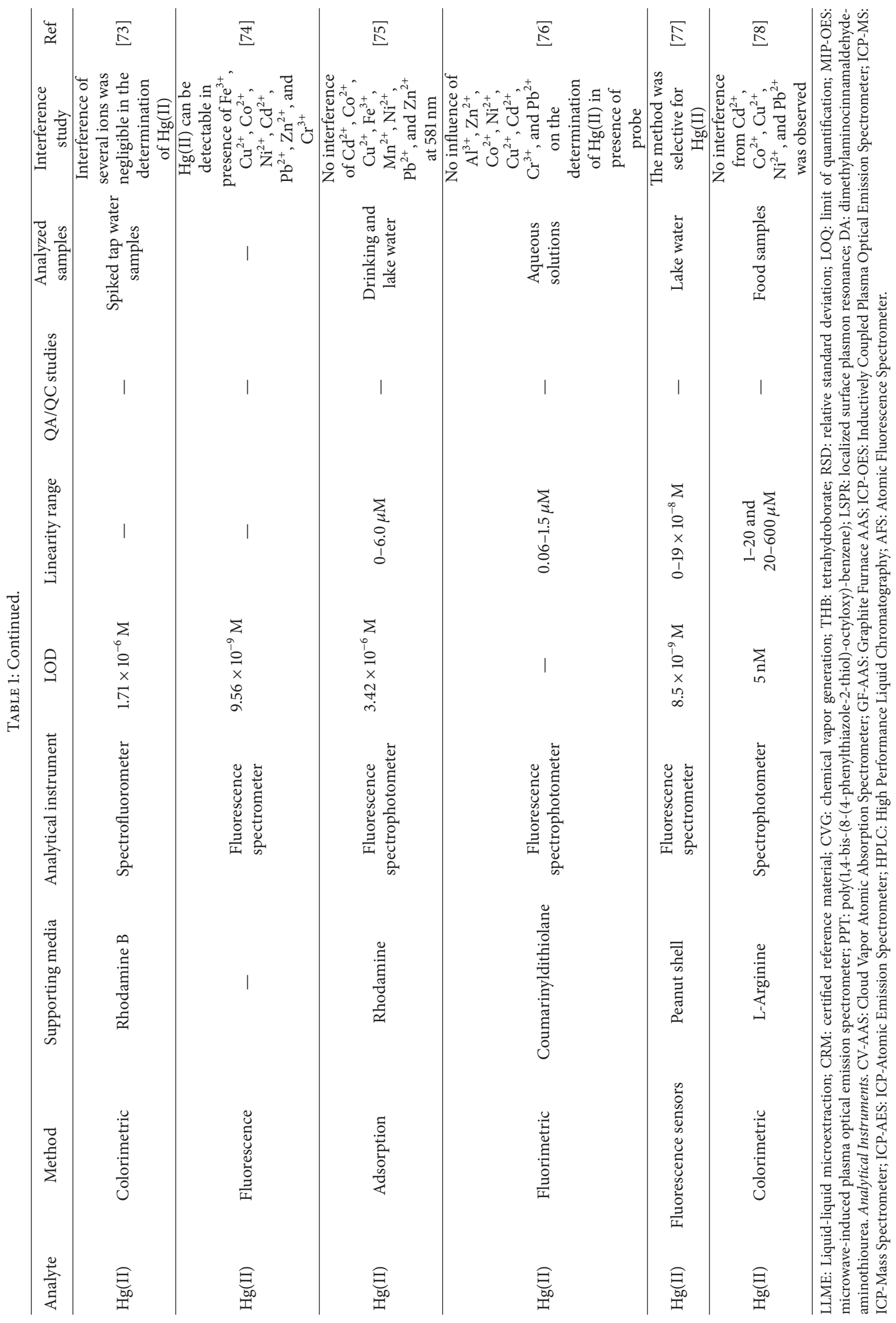




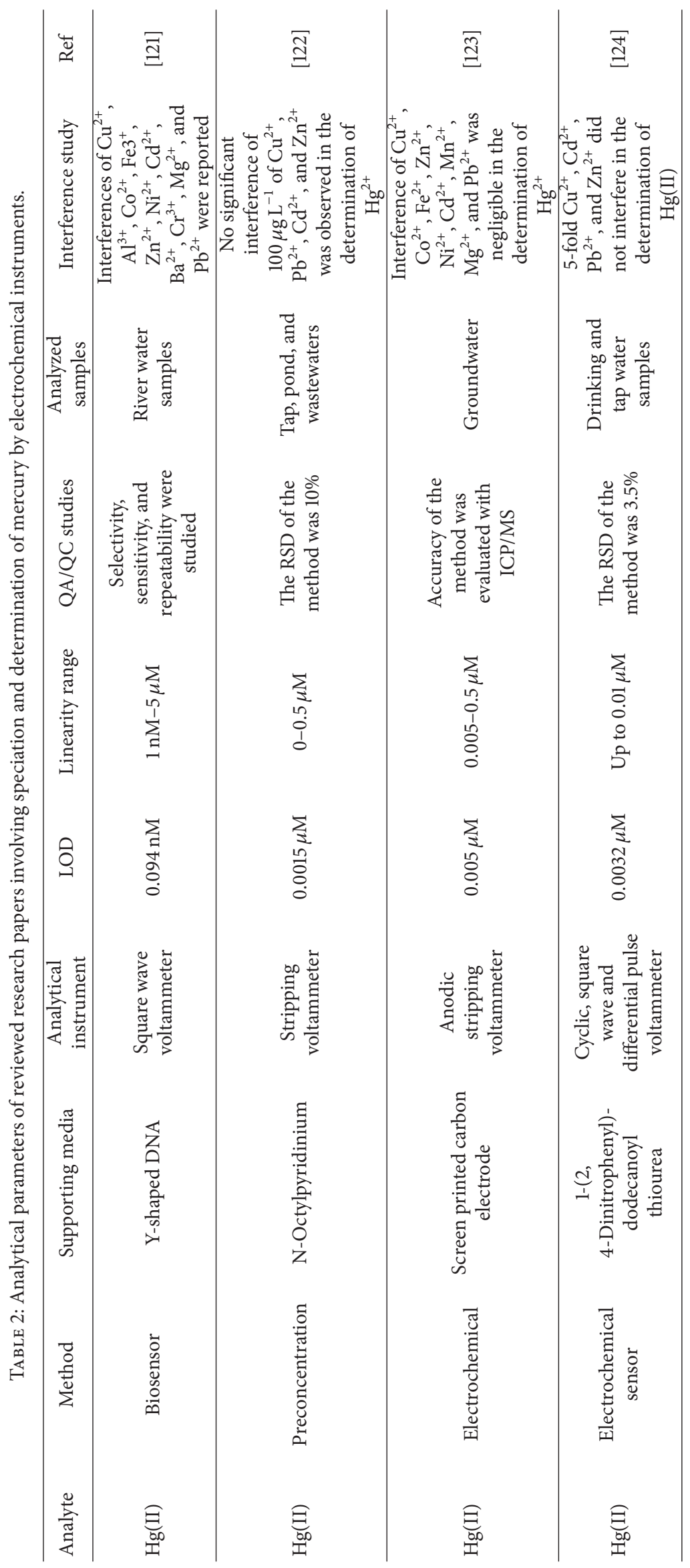




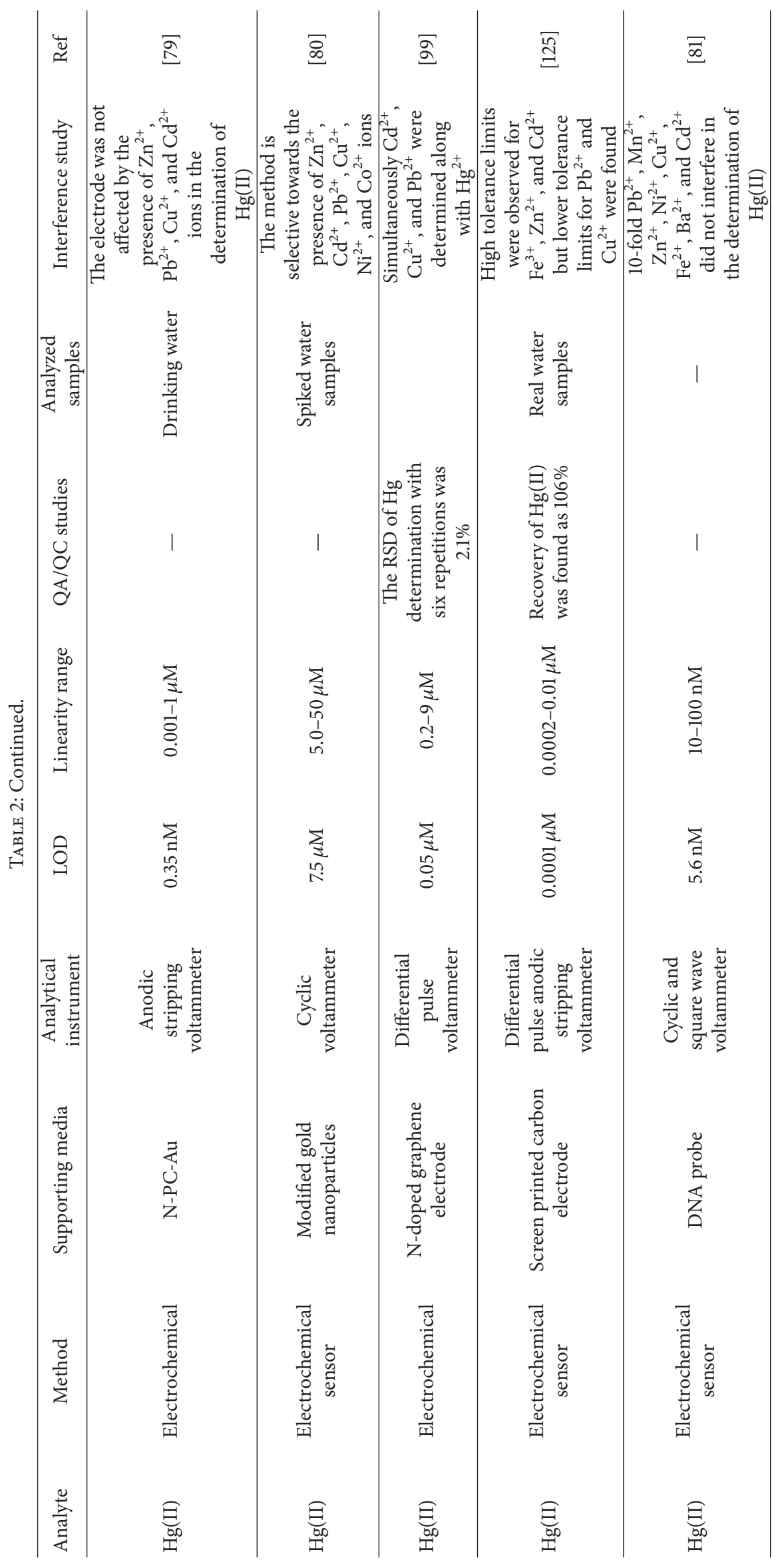




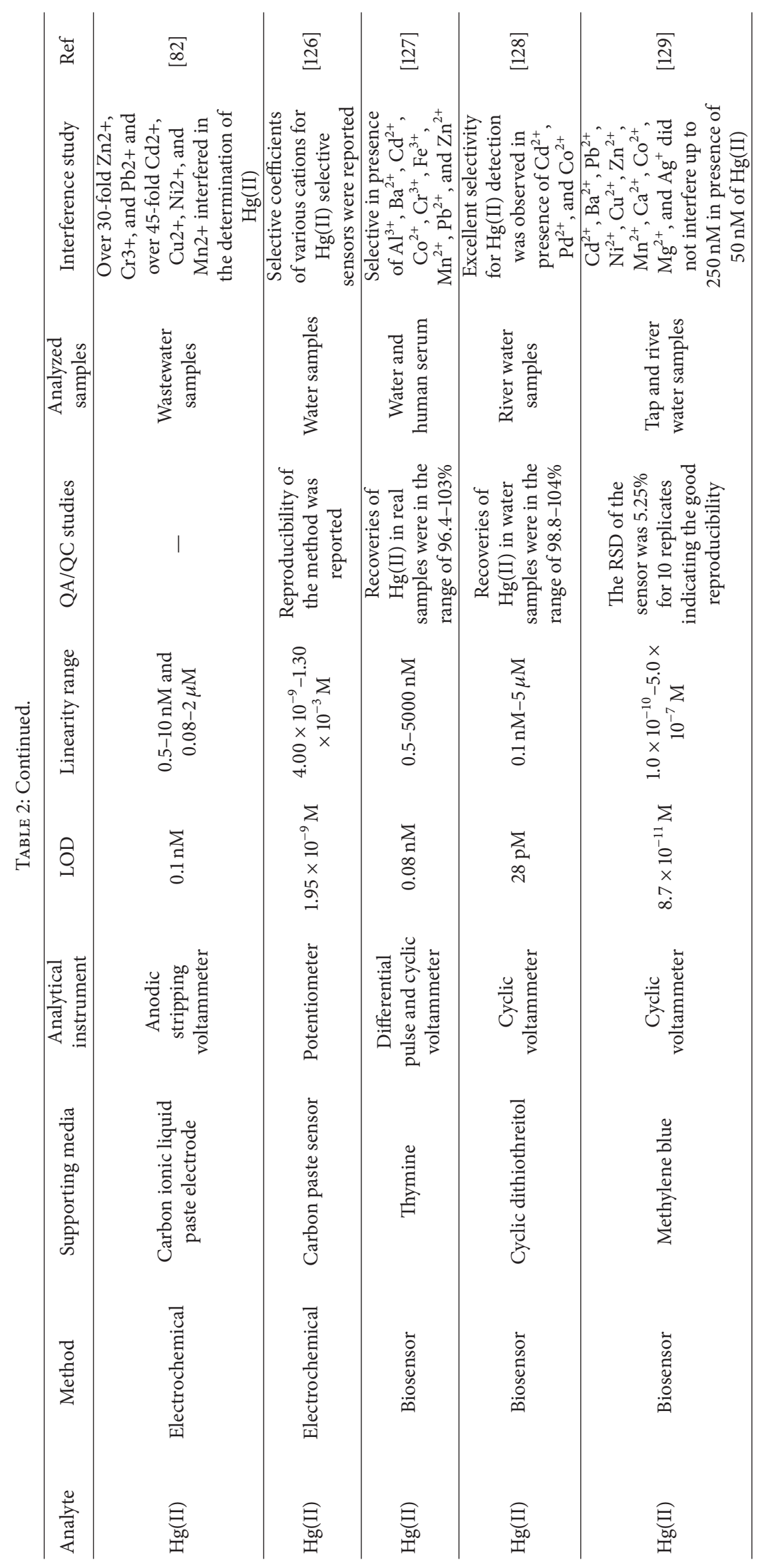




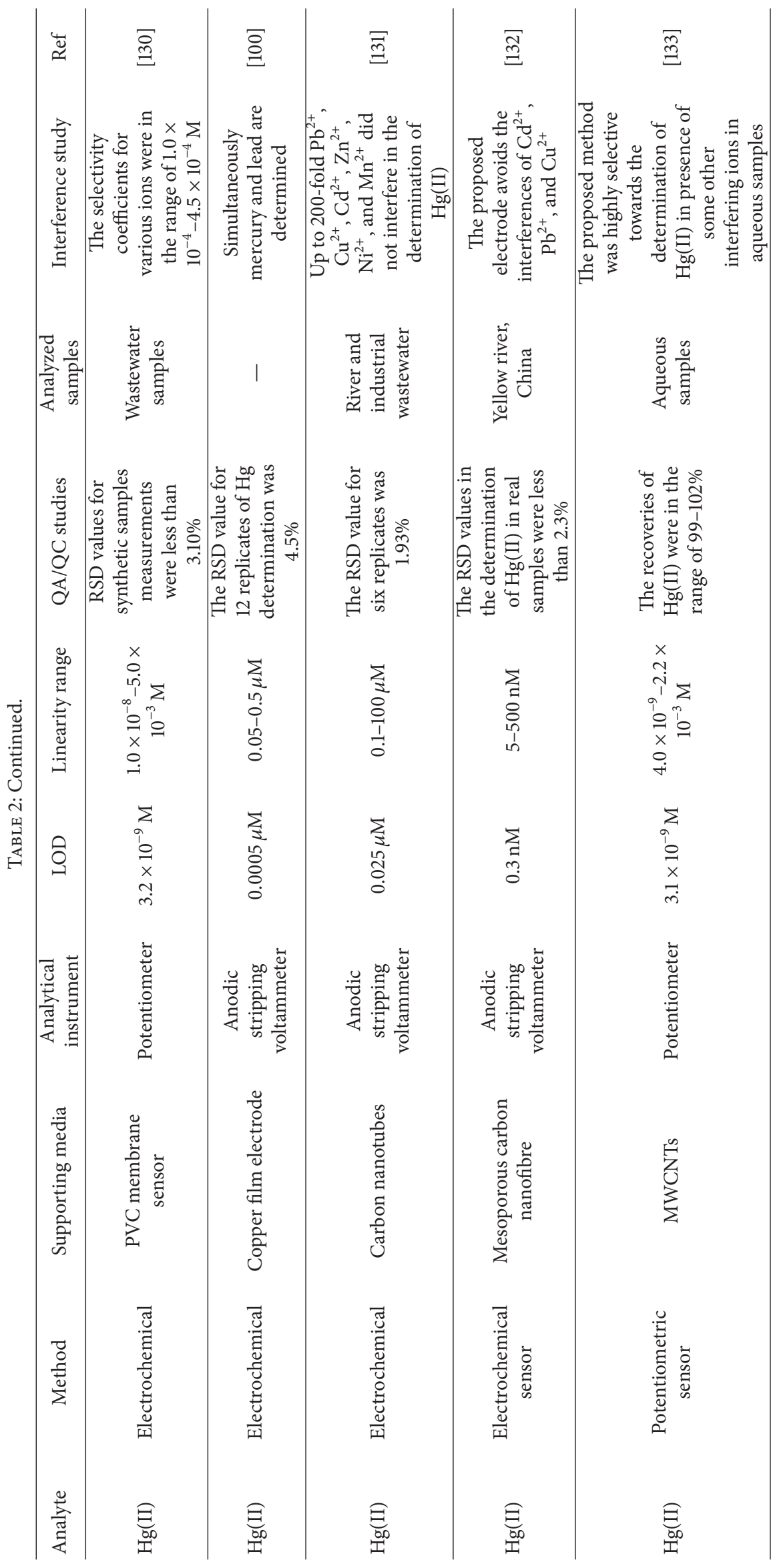




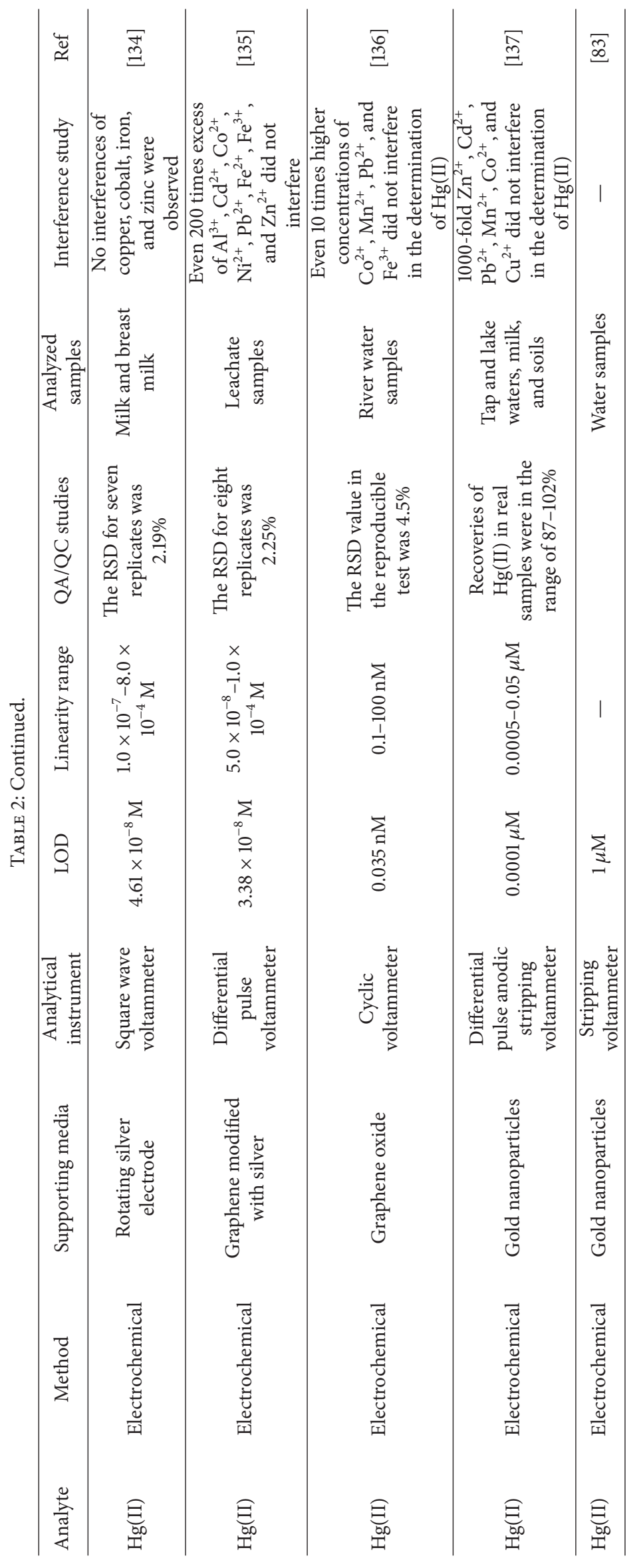




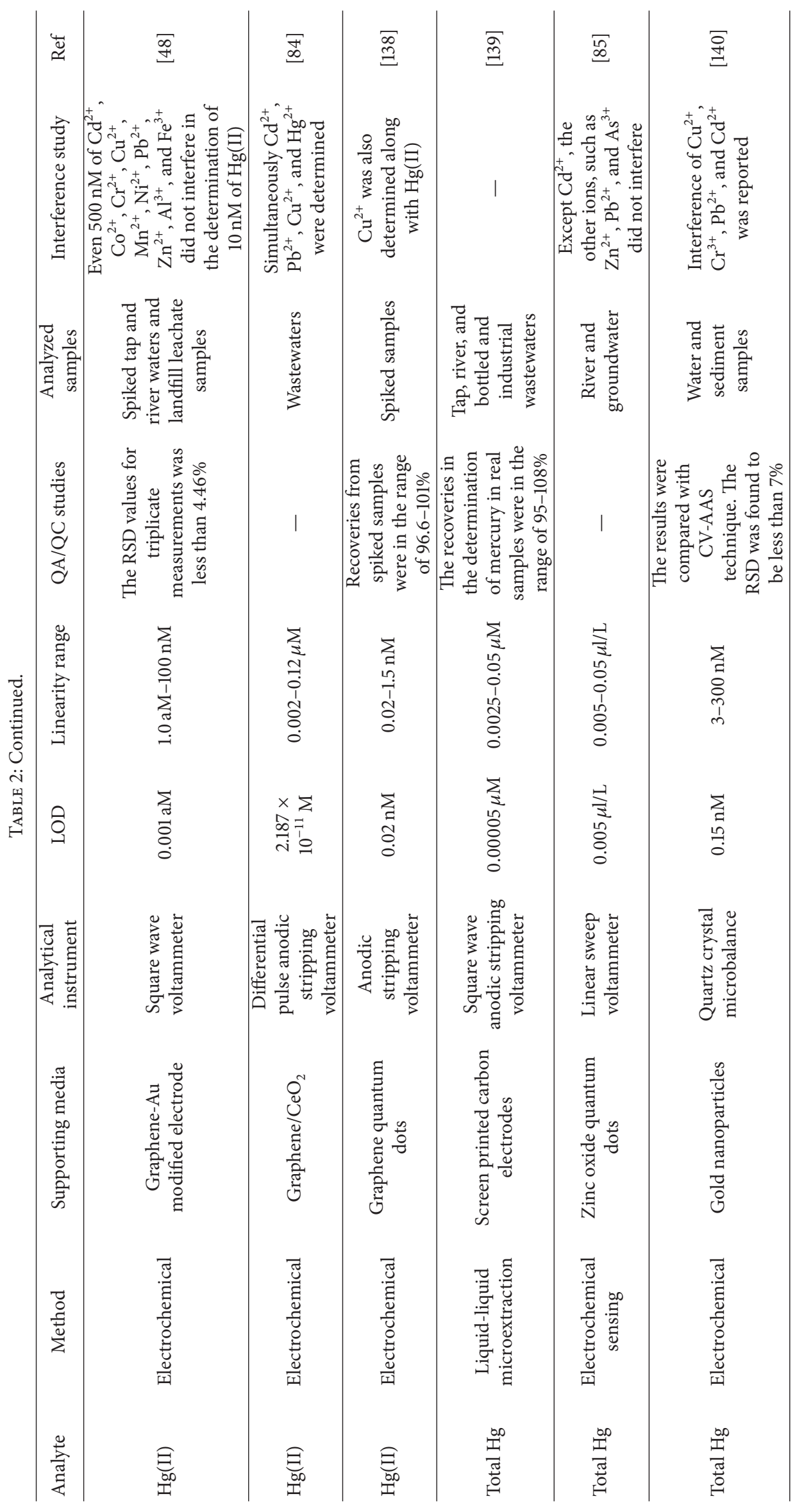




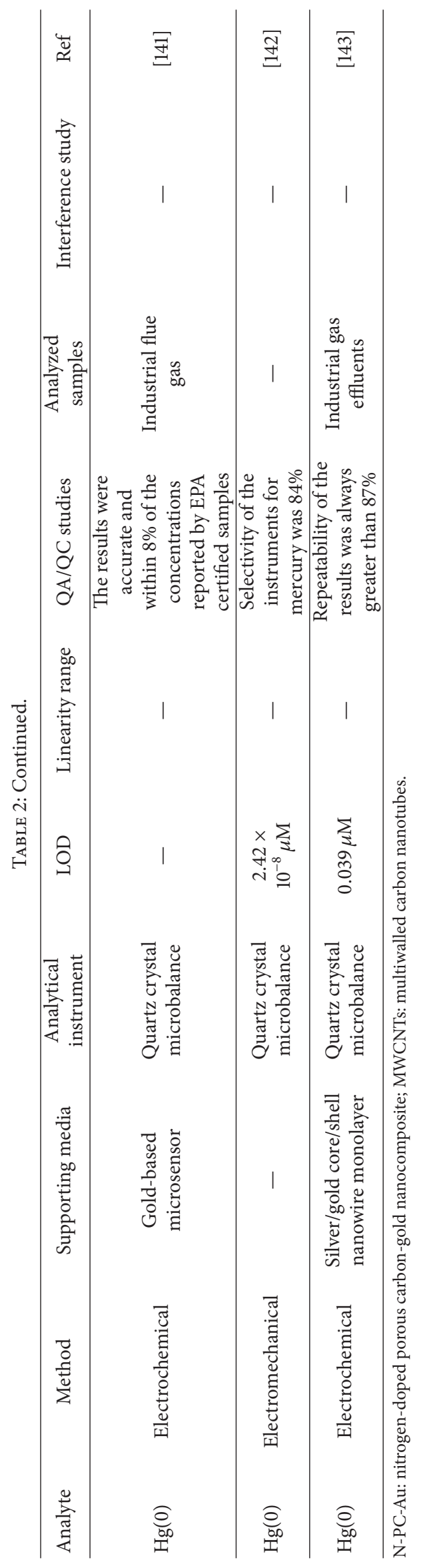




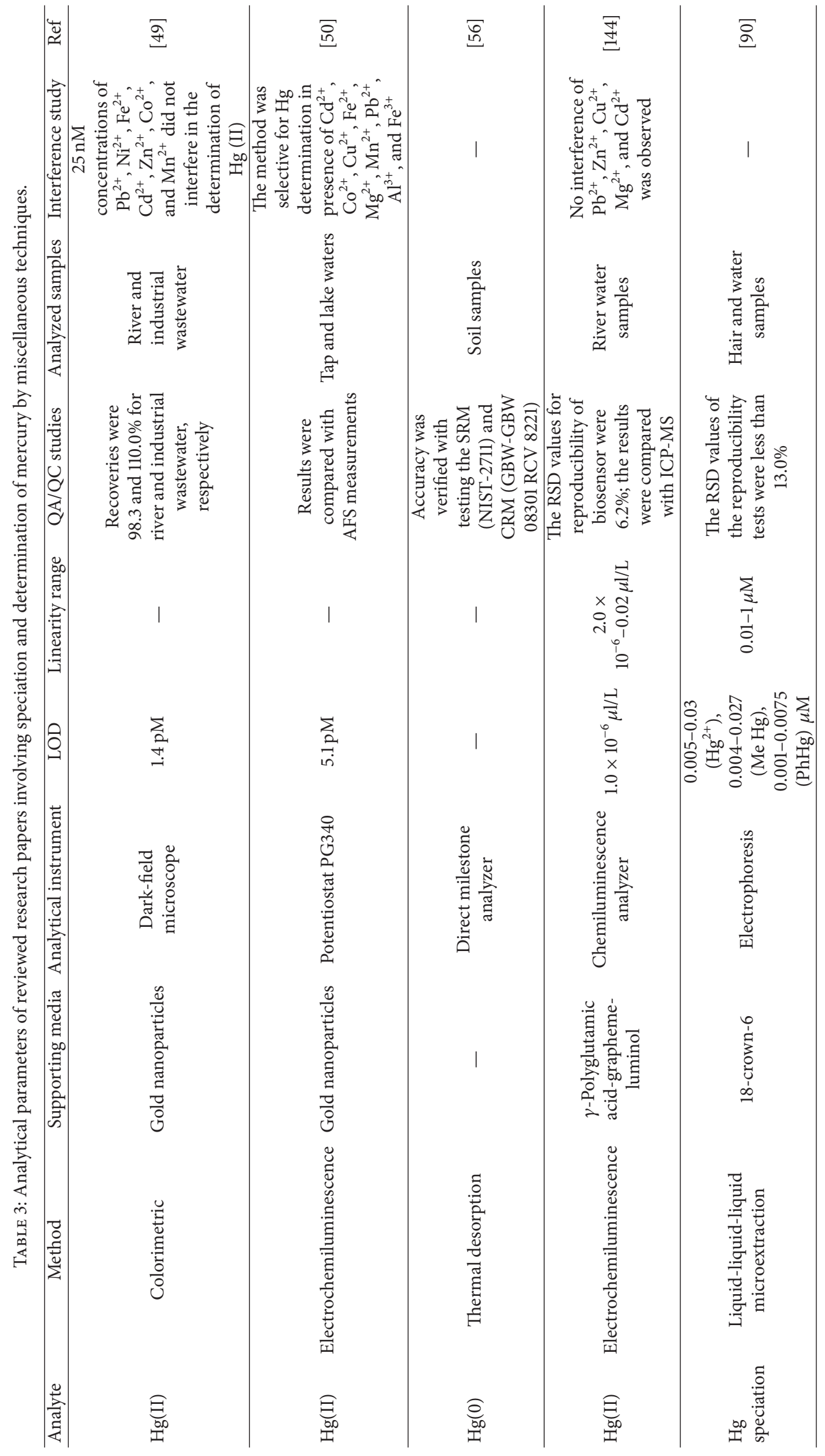




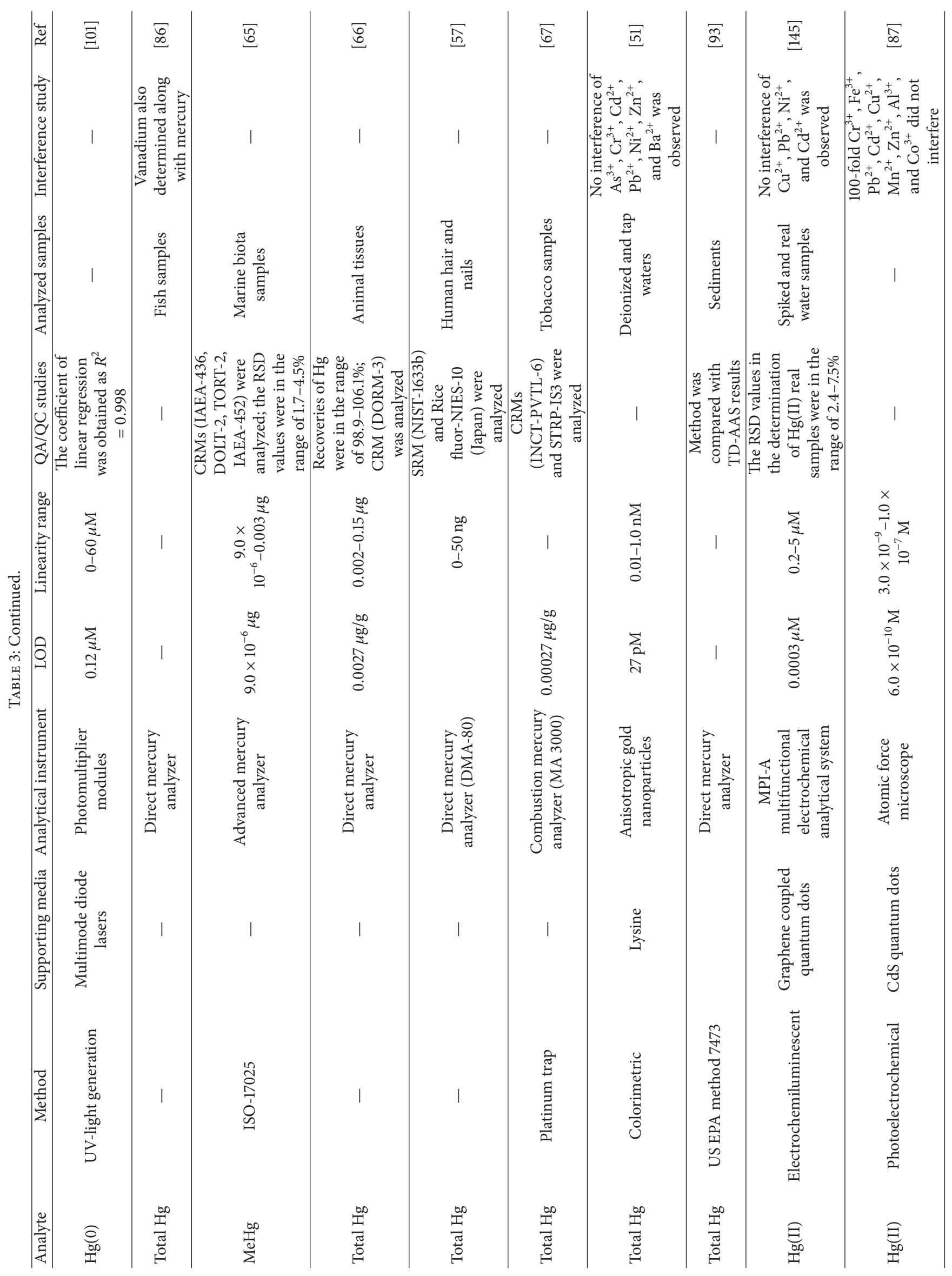


We conclude by stating that speciation studies and the determination of mercury in the atmosphere should receive greater attention in the future.

\section{Conflicts of Interest}

The authors declare that there are no conflicts of interest regarding the publication of this article.

\section{References}

[1] F. P. Arantes, L. A. Savassi, H. B. Santos, M. V. T. Gomes, and N. Bazzoli, "Bioaccumulation of mercury, cadmium, zinc, chromium, and lead in muscle, liver, and spleen tissues of a large commercially valuable catfish species from Brazil," Anais da Academia Brasileira de Ciências, vol. 88, no. 1, pp. 137-147, 2016.

[2] W. R. Bastos, J. G. Dórea, J. V. E. Bernardi et al., "Sex-related mercury bioaccumulation in fish from the Madeira River, Amazon," Environmental Research, vol. 144, pp. 73-80, 2016.

[3] I. B. Øverjordet, G. W. Gabrielsen, T. Berg et al., "Effect of diet, location and sampling year on bioaccumulation of mercury, selenium and cadmium in pelagic feeding seabirds in Svalbard," Chemosphere, vol. 122, pp. 14-22, 2015.

[4] J. Li, Q. Zhou, G. Yuan, X. He, and P. Xie, "Mercury bioaccumulation in the food web of Three Gorges Reservoir (China): tempo-spatial patterns and effect of reservoir management," Science of the Total Environment, vol. 527-528, pp. 203-210, 2015.

[5] F. Dang, J. Zhao, B. K. Greenfield et al., "Soil geochemistry and digestive solubilization control mercury bioaccumulation in the earthworm Pheretima guillemi," Journal of Hazardous Materials, vol. 292, pp. 44-51, 2015.

[6] K. J. Gosnell and R. P. Mason, "Mercury and methylmercury incidence and bioaccumulation in plankton from the central Pacific Ocean," Marine Chemistry, vol. 177, pp. 772-780, 2015.

[7] M. Banaee, S. Mohammadipour, and S. Madhani, "Effects of sublethal concentrations of permethrin on bioaccumulation of cadmium in zebra cichlid (Cichlasoma nigrofasciatum)," Toxicological \& Environmental Chemistry, vol. 97, no. 2, pp. 200207, 2015.

[8] O. Ouédraogo, J. Chételat, and M. Amyot, "Bioaccumulation and trophic transfer of mercury and selenium in African subtropical fluvial reservoirs food webs (Burkina Faso)," PLoS ONE, vol. 10, no. 4, Article ID e0123048, 2015.

[9] D. B. Donald, B. Wissel, and M. U. M. Anas, "Species-specific mercury bioaccumulation in a diverse fish community," Environmental Toxicology and Chemistry, vol. 34, no. 12, pp. 28462855, 2015.

[10] https://people.uwec.edu/piercech/Hg/mercury_water/ursoces .htm; accessed on 8th August, 2016.

[11] W. Zhuang and X. Gao, "Distributions, sources and ecological risk assessment of arsenic and mercury in the surface sediments of the southwestern coastal Laizhou Bay, Bohai Sea," Marine Pollution Bulletin, vol. 99, no. 1-2, pp. 320-327, 2015.

[12] S. Y. Kwon, J. D. Blum, K. J. Nadelhoffer, J. Timothy Dvonch, and M. T.-K. Tsui, "Isotopic study of mercury sources and transfer between a freshwater lake and adjacent forest food web," Science of the Total Environment, vol. 532, pp. 220-229, 2015.

[13] J. Xu, A. G. Bravo, A. Lagerkvist, S. Bertilsson, R. Sjöblom, and J. Kumpiene, "Sources and remediation techniques for mercury contaminated soil," Environment International, vol. 74, pp. 42$53,2014$.
[14] M. Shamsipur, H. R. Rajabi, M. H. Beyzavi, and H. Sharghi, "Bulk polymer nanoparticles containing a tetrakis(3-hydroxyphenyl)porphyrin for fast and highly selective separation of mercury ions," Microchimica Acta, vol. 180, no. 9-10, pp. 791799, 2013.

[15] H. R. Rajabi, M. Roushani, and M. Shamsipur, "Development of a highly selective voltammetric sensor for nanomolar detection of mercury ions using glassy carbon electrode modified with a novel ion imprinted polymeric nanobeads and multi-wall carbon nanotubes," Journal of Electroanalytical Chemistry, vol. 693, pp. 16-22, 2013.

[16] J.-S. Han, Y.-S. Seo, M.-K. Kim, T. M. Holsen, and S.-M. Yi, "Total atmospheric mercury deposition in forested areas in South Korea," Atmospheric Chemistry and Physics, vol. 16, no. 12, pp. 7653-7662, 2016.

[17] X. Xu, N. Liu, M. S. Landis, X. Feng, and G. Qiu, "Characteristics and distributions of atmospheric mercury emitted from anthropogenic sources in Guiyang, southwestern China," Acta Geochimica, vol. 35, no. 3, pp. 240-250, 2016.

[18] M. Yoshida, J. Lee, H. Shimizu-Furusawa, M. Satoh, and C. Watanabe, "Neurobehavioral toxicity related to the exposure of weaning mice to low-level mercury vapor and methylmercury and influence of aging," Fundamental Toxicological Sciences, vol. 3, no. 4, pp. 185-193, 2016.

[19] L. Bucio, V. Souza, A. Albores et al., "Cadmium and mercury toxicity in a human fetal hepatic cell line (WRL-68 cells)," Toxicology, vol. 102, no. 3, pp. 285-299, 1995.

[20] M. Farina, D. S. Avila, J. B. T. Da Rocha, and M. Aschner, "Metals, oxidative stress and neurodegeneration: A focus on iron, manganese and mercury," Neurochemistry International, vol. 62, no. 5, pp. 575-594, 2013.

[21] M. A. Al-Batanony, G. M. Abdel-Rasul, M. A. Abu-Salem, M. M. Al-Dalatony, and H. K. Allam, "Occupational exposure to mercury among workers in a fluorescent lamp factory, Quisna industrial zone, Egypt," International Journal of Occupational Medicine and Environmental Health, vol. 4, no. 3, pp. 149-156, 2013.

[22] C. M. L. Carvalho, E.-H. Chew, S. I. Hashemy, J. Lu, and A. Holmgren, "Inhibition of the human thioredoxin system: A molecular mechanism of mercury toxicity," The Journal of Biological Chemistry, vol. 283, no. 18, pp. 11913-11923, 2008.

[23] R. A. Bernhoft, "Mercury toxicity and treatment: a review of the literature," Journal of Environmental and Public Health, vol. 2012, Article ID 460508, 10 pages, 2012.

[24] A. Tonazzi, N. Giangregorio, L. Console et al., "Mitochondrial Carnitine/Acylcarnitine Transporter, a Novel Target of Mercury Toxicity," Chemical Research in Toxicology, vol. 28, no. 5, pp. 1015-1022, 2015.

[25] F. Xu, S. Farkas, S. Kortbeek et al., "Mercury-induced toxicity of rat cortical neurons is mediated through $\mathrm{N}$-methyl-D-Aspartate receptors," Molecular Brain, vol. 5, article 30, 2012.

[26] J. G. Dórea, M. Farina, and J. B. T. Rocha, “Toxicity of ethylmercury (and Thimerosal): a comparison with methylmercury," Journal of Applied Toxicology, vol. 33, no. 8, pp. 700-711, 2013.

[27] M. C. Houston, "Role of mercury toxicity in hypertension, cardiovascular disease, and stroke," The Journal of Clinical Hypertension, vol. 13, no. 8, pp. 621-627, 2011.

[28] K. M. Rice, E. M. Walker Jr., M. Wu, C. Gillette, and E. R. Blough, "Environmental mercury and its toxic effects," Journal of Preventive Medicine \& Public Health, vol. 47, no. 2, pp. 74-83, 2014. 
[29] M. Patra and A. Sharma, "Mercury toxicity in plants," The Botanical Review, vol. 66, no. 3, pp. 379-422, 2000.

[30] D. Cargnelutti, L. A. Tabaldi, R. M. Spanevello et al., "Mercury toxicity induces oxidative stress in growing cucumber seedlings," Chemosphere, vol. 65, no. 6, pp. 999-1006, 2006.

[31] J. Chen and Z. M. Yang, "Mercury toxicity, molecular response and tolerance in higher plants," BioMetals, vol. 25, no. 5, pp. 847857, 2012.

[32] D. E. L. Hanna, C. T. Solomon, A. E. Poste, D. G. Buck, and L. J. Chapman, "A review of mercury concentrations in freshwater fishes of Africa: Patterns and predictors," Environmental Toxicology and Chemistry, vol. 34, no. 2, pp. 215-223, 2015.

[33] S. L. C. Ferreira, V. A. Lemos, L. O. B. Silva et al., "Analytical strategies of sample preparation for the determination of mercury in food matrices-a review," Microchemical Journal, vol. 121, pp. 227-236, 2015.

[34] W. Chansuvarn, T. Tuntulani, and A. Imyim, "Colorimetric detection of mercury(II) based on gold nanoparticles, fluorescent gold nanoclusters and other gold-based nanomaterials," TrAC - Trends in Analytical Chemistry, vol. 65, pp. 83-96, 2015.

[35] P. A. Ariya, M. Amyot, A. Dastoor et al., "Mercury physicochemical and biogeochemical transformation in the atmosphere and at atmospheric interfaces: a review and future directions," Chemical Reviews, vol. 115, no. 10, pp. 3760-3802, 2015.

[36] S. Shrivastava, A. Shrivastav, and J. Sharma, "Detoxification mechanisms of mercury toxicity in plants: a review," Recent Advances in Biology and Medicine, vol. 01, p. 60, 2015.

[37] K. Duarte, C. I. L. Justino, A. C. Freitas, A. M. P. Gomes, A. C. Duarte, and T. A. P. Rocha-Santos, "Disposable sensors for environmental monitoring of lead, cadmium and mercury," TrAC Trends in Analytical Chemistry, vol. 64, pp. 183-190, 2015.

[38] R. Jagtap and W. Maher, "Measurement of mercury species in sediments and soils by HPLC-ICPMS," Microchemical Journal, vol. 121, pp. 65-98, 2015.

[39] M. S. Gustin, H. M. Amos, J. Huang, M. B. Miller, and K. Heidecorn, "Measuring and modeling mercury in the atmosphere: a critical review," Atmospheric Chemistry and Physics, vol. 15, no. 10, pp. 5697-5713, 2015.

[40] D. S. McLagan, M. E. Mazur, C. P. Mitchell, and F. Wania, "Passive air sampling of gaseous elemental mercury: a critical review," Atmospheric Chemistry and Physics Discussions, vol. 15, no. 23, pp. 34605-34645, 2015.

[41] B. P. Jackson and T. Punshon, "Recent advances in the measurement of arsenic, cadmium, and mercury in rice and other foods," Current Environmental Health Reports, vol. 2, no. 1, pp. 15-24, 2015.

[42] J. Duan and J. Zhan, "Recent developments on nanomaterialsbased optical sensors for Hg2+ detection," Science China Materials, vol. 58, no. 3, pp. 223-240, 2015.

[43] Z. Sun, J. Du, and C. Jing, "Recent progress in detection of mercury using surface enhanced Raman spectroscopy - a review," Journal of Environmental Sciences, vol. 39, pp. 134-143, 2016.

[44] L. N. Suvarapu and S.-O. Baek, "Recent developments in the speciation and determination of mercury using various analytical techniques," Journal of Analytical Methods in Chemistry, vol. 2015, Article ID 372459, 18 pages, 2015.

[45] X. Chen, R. Balasubramanian, Q. Zhu et al., "Characteristics of atmospheric particulate mercury in size-fractionated particles during haze days in Shanghai," Atmospheric Environment, vol. 131, pp. 400-408, 2016.
[46] K. Marumoto and S. Imai, "Determination of dissolved gaseous mercury in seawater of Minamata Bay and estimation for mercury exchange across air-sea interface," Marine Chemistry, vol. 168, pp. 9-17, 2015.

[47] C.-C. Brombach, B. Chen, W. T. Corns, J. Feldmann, and E. M. Krupp, "Methylmercury in water samples at the pg/L level by online preconcentration liquid chromatography cold vaporatomic fluorescence spectrometry," Spectrochimica Acta Part B: Atomic Spectroscopy, vol. 105, pp. 103-108, 2015.

[48] Y. Zhang, G. M. Zeng, L. Tang et al., "Electrochemical sensor based on electrodeposited graphene-au modified electrode and nanoau carrier amplified signal strategy for attomolar mercury detection," Analytical Chemistry, vol. 87, no. 2, pp. 989-996, 2015.

[49] X. Liu, Z. Wu, Q. Zhang, W. Zhao, C. Zong, and H. Gai, "Single gold nanoparticle-based colorimetric detection of picomolar mercury ion with dark-field microscopy," Analytical Chemistry, vol. 88, no. 4, pp. 2119-2124, 2016.

[50] R.-F. Huang, H.-X. Liu, Q.-Q. Gai, G.-J. Liu, and Z. Wei, “A facile and sensitive electrochemiluminescence biosensor for $\mathrm{Hg}^{2+}$ analysis based on a dual-function oligonucleotide probe," Biosensors and Bioelectronics, vol. 71, pp. 194-199, 2015.

[51] A. Chaudhary, C. Dwivedi, M. Chawla, A. Gupta, and C. K. Nandi, "Lysine and dithiothreitol promoted ultrasensitive optical and colorimetric detection of mercury using anisotropic gold nanoparticles," Journal of Materials Chemistry C, vol. 3, no. 27, pp. 6962-6965, 2015.

[52] J. C. Miller and J. N. Miller, Statistics for Analytical Chemistry, Ellis Horwood Limited, England, 2nd edition, 1988.

[53] S. De Oliveira Souza, L. L. François, A. R. Borges, M. G. R. Vale, and R. G. O. Araujo, "Determination of copper and mercury in phosphate fertilizers employing direct solid sampling analysis and high resolution continuum source graphite furnace atomic absorption spectrometry," Spectrochimica Acta Part B: Atomic Spectroscopy, vol. 114, pp. 58-64, 2015.

[54] E. Ghorbani-Kalhor, R. Hosseinzadeh-Khanmiri, J. Abolhasani, M. Babazadeh, and A. Hassanpour, "Determination of mercury(II) ions in seafood samples after extraction and preconcentration by a novel functionalized magnetic metal-organic framework nanocomposite," Journal of Separation Science, vol. 38, no. 7, pp. 1179-1186, 2015.

[55] P. Mandjukov, A. M. Orani, E. Han, and E. Vassileva, "Determination of total mercury for marine environmental monitoring studies by solid sampling continuum source high resolution atomic absorption spectrometry," Spectrochimica Acta Part B: Atomic Spectroscopy, vol. 103-104, pp. 24-33, 2015.

[56] L. C. Soares, F. B. Egreja Filho, L. A. Linhares, C. C. Windmoller, and M. I. Yoshida, "Accumulation and oxidation of elemental mercury in tropical soils," Chemosphere, vol. 134, pp. 181-191, 2015.

[57] A. Vicent, M. L. Cervera, and A. M. Rubio, "Fast and accurate methodology for direct mercury determination in hair and nails," Sample Preparation, vol. 2, no. 1, pp. 91-98, 2015.

[58] Y. Li, Z. Zhu, H. Zheng, L. Jin, and S. Hu, "Significant signal enhancement of dielectric barrier discharge plasma induced vapor generation by using non-ionic surfactants for determination of mercury and cadmium by atomic fluorescence spectrometry," Journal of Analytical Atomic Spectrometry, vol. 31, no. 2, pp. 383-389, 2016.

[59] H. Pietilä, P. Perämäki, J. Piispanen et al., "Determination of low methylmercury concentrations in peat soil samples by isotope 
dilution GC-ICP-MS using distillation and solvent extraction methods," Chemosphere, vol. 124, no. 1, pp. 47-53, 2015.

[60] N. A. Panichev and S. E. Panicheva, "Determination of total mercury in fish and sea products by direct thermal decomposition atomic absorption spectrometry," Food Chemistry, vol. 166, pp. 432-441, 2015.

[61] R. Sánchez, J. Snell, A. Held, and H. Emons, "Development and validation of a method for mercury determination in seawater for the process control of a candidate certified reference material," Analytical and Bioanalytical Chemistry, vol. 407, no. 21, pp. 6569-6574, 2015.

[62] R. Fernández-Martínez, I. Rucandio, I. Gómez-Pinilla, F. Borlaf, F. García, and M. T. Larrea, "Evaluation of different digestion systems for determination of trace mercury in seaweeds by cold vapour atomic fluorescence spectrometry," Journal of Food Composition and Analysis, vol. 38, pp. 7-12, 2015.

[63] S. Döker and I. I. Boşgelmez, "Rapid extraction and reverse phase-liquid chromatographic separation of mercury(II) and methylmercury in fish samples with inductively coupled plasma mass spectrometric detection applying oxygen addition into plasma," Food Chemistry, vol. 184, Article ID 17314, pp. 147-153, 2015.

[64] Z. Chen, C. Zhang, H. Ma et al., "A non-aggregation spectrometric determination for mercury ions based on gold nanoparticles and thiocyanuric acid," Talanta, vol. 134, pp. 603-606, 2015.

[65] S. Azemard and E. Vassileva, "Determination of methylmercury in marine biota samples with advanced mercury analyzer: method validation," Food Chemistry, vol. 176, pp. 367-375, 2015.

[66] R. F. L. Ribeiro and A. Germano, "Development and validation of a method for the determination of $\mathrm{Hg}$ in animal tissues (equine muscle, bovine kidney and swine kidney, and poultry muscle) by direct mercury analysis (DMA)," Microchemical Journal, vol. 121, pp. 237-243, 2015.

[67] M. R. Fresquez, N. Gonzalez-Jimenez, N. Gray, C. H. Watson, and R. S. Pappas, "High-throughput determination of mercury in tobacco and mainstream smoke from little cigars," Journal of Analytical Toxicology, vol. 39, no. 7, pp. 545-550, 2015.

[68] A. Mortazavi, M. Hatamikia, M. Bahmani, and H. Hassanzadazar, "Heavy metals (mercury, lead and cadmium) determination of 17 species of fish marketed in Khorramabad city, west of Iran," Journal of Chemical Health Risks, vol. 6, no. 1, pp. 41-48, 2016.

[69] N. P. Minh, "Determination of mercury in seafood by atomic emission spectrophotometry," Bulletin of Environment, Pharmacology and Life Sciences, vol. 4, no. 7, pp. 41-47, 2015.

[70] K. D. Bhatt, D. J. Vyas, B. A. Makwana, S. M. Darjee, V. K. Jain, and H. Shah, "Turn-on fluorescence probe for selective detection of $\mathrm{Hg}(\mathrm{II})$ by calixpyrrole hydrazide reduced silver nanoparticle: Application to real water sample," Chinese Chemical Letters, vol. 27, no. 5, pp. 731-737, 2016.

[71] Z. Geng, H. Zhang, Q. Xiong, Y. Zhang, H. Zhao, and G. Wang, "A fluorescent chitosan hydrogel detection platform for the sensitive and selective determination of trace mercury(II) in water," Journal of Materials Chemistry A, vol. 3, no. 38, pp. 19455-19460, 2015.

[72] K. Velmurugan and R. Nandhakumar, "Binol based 'turn on' fluorescent chemosensor for mercury ion," Journal of Luminescence, vol. 162, pp. 8-13, 2015.

[73] S. Erdemir, O. Kocyigit, and S. Malkondu, "Detection of $\mathrm{Hg} 2+$ ion in aqueous media by new fluorometric and colorimetric sensor based on triazole-rhodamine," Journal of Photochemistry and Photobiology A: Chemistry, vol. 309, article no. 9880, pp. 1521, 2015.

[74] J. Hu, J. Li, J. Qi, and J. Chen, "Highly selective and effective mercury(II) fluorescent sensors," New Journal of Chemistry, vol. 39, no. 2, pp. 843-848, 2015.

[75] D. Shi, F. Yan, M. Wang et al., "Rhodamine derivative functionalized chitosan as efficient sensor and adsorbent for mercury(II) detection and removal," Materials Research Bulletin, vol. 70, pp. 958-964, 2015.

[76] Y. Guo, J. An, H. Tang, M. Peng, and F. Suzenet, "Selective and 'turn-off' fluorimetric detection of mercury(II) based on coumarinyldithiolane and coumarinyldithiane in aqueous solution," Materials Research Bulletin, vol. 63, pp. 155-163, 2015.

[77] M. Wang, G. Meng, and Q. Huang, "Spinach-extracted chlorophyll-a modified peanut shell as fluorescence sensors for selective detection of $\mathrm{Hg} 2+$ in water," Sensors and Actuators B: Chemical, vol. 209, pp. 237-241, 2015.

[78] J. Guan, Y.-C. Wang, and S. Gunasekaran, "Using L-ArginineFunctionalized Gold Nanorods for Visible Detection of Mercury(II) Ions," Journal of Food Science, vol. 80, no. 4, pp. N828N833, 2015.

[79] Q. Guan, W. Xiong, L. Zhou, and S. Liu, "Facile synthesis of nitrogen-doped porous carbon-gold hybrid nanocomposite for mercury(II) ion electrochemical determination," Electroanalysis, vol. 28, no. 1, pp. 133-139, 2016.

[80] N. Wang, M. Lin, H. Dai, and H. Ma, "Functionalized gold nanoparticles/reduced graphene oxide nanocomposites for ultrasensitive electrochemical sensing of mercury ions based on thymine-mercury-thymine structure," Biosensors and Bioelectronics, vol. 79, pp. 320-326, 2016.

[81] B. Jiang, L. Yu, F. Li, and J. Xie, "A dual functional electrochemical 'on-off' switch sensor for the detection of mercury(II) and melamine," Sensors and Actuators B: Chemical, vol. 212, pp. 446450, 2015.

[82] A. Bahrami, A. Besharati-Seidani, A. Abbaspour, and M. Shamsipur, "A highly selective voltammetric sensor for nanomolar detection of mercury ions using a carbon ionic liquid paste electrode impregnated with novel ion imprinted polymeric nanobeads," Materials Science and Engineering C: Materials for Biological Applications, vol. 48, pp. 205-212, 2015.

[83] N. Ratner and D. Mandler, "Electrochemical detection of low concentrations of mercury in water using gold nanoparticles," Analytical Chemistry, vol. 87, no. 10, pp. 5148-5155, 2015.

[84] Y.-L. Xie, S.-Q. Zhao, H.-L. Ye, J. Yuan, P. Song, and S.-Q. $\mathrm{Hu}$, "Graphene/CeO2 hybrid materials for the simultaneous electrochemical detection of cadmium(II), lead(II), copper(II), and mercury(II)," Journal of Electroanalytical Chemistry, vol. 757, pp. 235-242, 2015.

[85] G. Bhanjana, N. Dilbaghi, R. Kumar, and S. Kumar, "Zinc oxide quantum dots as efficient electron mediator for ultrasensitive and selective electrochemical sensing of mercury," Electrochimica Acta, vol. 178, Article ID 25395, pp. 361-367, 2015.

[86] N. J. H. Fard, M. Ravanbakhsh, Z. Ramezani, M. Ahmadi, K. A. Angali, and A. Z. Javid, "Determination of mercury and vanadium concentration in Johnius belangerii (C) fish in Musa estuary in Persian Gulf," Marine Pollution Bulletin, vol. 97, no. 1-2, pp. 499-505, 2015.

[87] D.-M. Han, L.-Y. Jiang, W.-Y. Tang, J.-J. Xu, and H.-Y. Chen, "Photoelectrochemical determination of inorganic mercury ions based on energy transfer between CdS quantum dots and 
Au nanoparticles," Electrochemistry Communications, vol. 51, pp. 72-75, 2015.

[88] Z. Gajdosechova, M. S. Boskamp, F. Lopez-Linares, J. Feldmann, and E. M. Krupp, "Hg speciation in petroleum hydrocarbons with emphasis on the reactivity of Hg particles," Energy \& Fuels, vol. 30, no. 1, pp. 130-137, 2016.

[89] X. Wen, Y. Gao, P. Wu, Z. Tan, C. Zheng, and X. Hou, “Chemical vapor generation from an ionic liquid using a solid reductant: determination of $\mathrm{Hg}$, As and $\mathrm{Sb}$ by atomic fluorescence spectrometry," Journal of Analytical Atomic Spectrometry, vol. 31, no. 2, pp. 415-422, 2016.

[90] P. Li, M. He, B. Chen, and B. Hu, "Automated dynamic hollow fiber liquid-liquid-liquid microextraction combined with capillary electrophoresis for speciation of mercury in biological and environmental samples," Journal of Chromatography A, vol. 1415, pp. 48-56, 2015.

[91] M. T. Lisboa, C. D. Clasen, E. Q. Oreste, A. Schwingel Ribeiro, and M. A. Vieira, "Comparison between vapor generation methods coupled to atomic absorption spectrometry for determination of $\mathrm{Hg}$ in glycerin samples," ENERGY \& FUELS, vol. 29, no. 3, pp. 1635-1640, 2015.

[92] G. Leng, W. Chen, and Y. Wang, "Speciation analysis of mercury in sediments using ionic-liquid-based vortex-assisted liquidliquid microextraction combined with high-performance liquid chromatography and cold vapor atomic fluorescence spectrometry," Journal of Separation Science, vol. 38, no. 15, pp. 2684-2691, 2015.

[93] J. Chen, P. Chakravarty, G. R. Davidson et al., "Simultaneous determination of mercury and organic carbon in sediment and soils using a direct mercury analyzer based on thermal decomposition-atomic absorption spectrophotometry," Analytica Chimica Acta, vol. 871, pp. 9-17, 2015.

[94] K. Prasertboonyai, B. Liawraungrath, T. Pojanakaroon, and S. Liawraungrath, "Mercury(II) determination in commercial cosmetics and local Thai traditional medicines by flow injection spectrophotometry," International Journal of Cosmetic Science, vol. 38, no. 1, pp. 68-76, 2016.

[95] M. Shellaiah, Y. C. Rajan, P. Balu, and A. Murugan, "A pyrene based Schiff base probe for selective fluorescence turn-on detection of $\mathrm{Hg} 2+$ ions with live cell application," New Journal of Chemistry, vol. 39, no. 4, pp. 2523-2531, 2015.

[96] X. He, S. Zhu, H. Chen, Y. Wang, and H. Li, "A new fluorescent turn-on chemodosimeter for mercury(II) based on dithioacetal-substituted triphenylimidazole," Journal of Luminescence, vol. 173, pp. 218-222, 2016.

[97] X. He, D. Yang, H. Chen, W. Zheng, and H. Li, "A highly sensitive and reversible chemosensor for $\mathrm{Hg} 2+$ detection based on porphyrin-thymine conjugates," Journal of Molecular Recognition, 2015.

[98] N. K. Hien, N. C. Bao, N. T. Ai Nhung et al., "A highly sensitive fluorescent chemosensor for simultaneous determination of $\mathrm{Ag}(\mathrm{I}), \mathrm{Hg}(\mathrm{II})$, and $\mathrm{Cu}(\mathrm{II})$ ions: design, synthesis, characterization and application," Dyes and Pigments, vol. 116, pp. 89-96, 2015.

[99] H. Xing, J. Xu, X. Zhu et al., "Highly sensitive simultaneous determination of cadmium (II), lead (II), copper (II), and mercury (II) ions on N-doped graphene modified electrode," Journal of Electroanalytical Chemistry, vol. 760, pp. 52-58, 2016.

[100] V. Jovanovski, N. I. Hrastnik, and S. B. Hočevar, "Copper film electrode for anodic stripping voltammetric determination of trace mercury and lead," Electrochemistry Communications, vol. 57, pp. 1-4, 2015.
[101] H. Lin, X. Lou, W. Zhong, and S. He, "Continuous monitoring of elemental mercury employing low-cost multimode diode lasers," Measurement Science and Technology, vol. 26, no. 8, Article ID 085501, 2015.

[102] J. Ali, T. G. Kazi, H. I. Afridi et al., "The evaluation of sequentially extracted mercury fractions in Thar coal samples by using different extraction schemes," International Journal of Coal Geology, vol. 156, pp. 50-58, 2016.

[103] U. A. Barbosa, L. O. B. Silva, I. F. Dos Santos, S. L. C. Ferreira, and A. M. P. Dos Santos, "Determination of mercury in iron supplement using slurry sampling and cold vapor atomic absorption spectrometry," Current Analytical Chemistry, vol. 11, no. 1, pp. 44-49, 2015.

[104] P. De O Vicentino, D. M. Brum, and R. J. Cassella, "Development of a method for total $\mathrm{Hg}$ determination in oil samples by cold vapor atomic absorption spectrometry after its extraction induced by emulsion breaking," Talanta, vol. 132, pp. 733-738, 2015.

[105] D. P. Torres, I. R. B. Olivares, and H. M. Queiroz, "Estimate of the uncertainty in measurement for the determination of mercury in seafood by TDA AAS," Journal of Environmental Science and Health, Part B: Pesticides, Food Contaminants, and Agricultural Wastes, vol. 50, no. 8, pp. 622-631, 2015.

[106] D. P. Torres, M. B. Martins-Teixeira, S. Cadore, and H. M. Queiroz, "Method validation for control determination of mercury in fresh fish and shrimp samples by solid sampling thermal decomposition/amalgamation atomic absorption spectrometry," Journal of Environmental Science and Health, Part B: Pesticides, Food Contaminants, and Agricultural Wastes, vol. 50, no. 7, pp. 514-522, 2015.

[107] P. Samaddar and K. Sen, "Discrimination for inorganic and organic mercury species by cloud point extraction of polyethylene glycol," Journal of Environmental Chemical Engineering (JECE), vol. 4, no. 2, pp. 1862-1868, 2016.

[108] M. M. Silva Jr., L. O. Bastos Silva, D. J. Leao, W. N. Lopes dos Santos, B. Welz, and S. L. Costa Ferreira, "Determination of mercury in alcohol vinegar samples from Salvador, Bahia, Brazil," Food Control, vol. 47, pp. 623-627, 2015.

[109] A. Rohman and E. Wijayanti, "Development and validation of atomic absorption spectrometry for the determination of zinc and mercury analyzer for determination of mercury in cream cosmetics," Journal of Food and Pharmaceutical Sciences, vol. 3, pp. 23-26, 2015.

[110] J. J. Lee, Y. S. Kim, E. Nam, S. Y. Lee, M. H. Lim, and C. Kim, "A pet-based fluorometric chemosensor for the determination of mercury(II) and $\mathrm{pH}$, and hydrolysis reaction-based colorimetric detection of hydrogen sulfide," Dalton Transactions, vol. 45, no. 13, pp. 5700-5712, 2016.

[111] B. B. A. Francisco, A. A. Rocha, P. Grinberg, R. E. Sturgeon, and R. J. Cassella, "Determination of inorganic mercury in petroleum production water by inductively coupled plasma optical emission spectrometry following photochemical vapor generation," Journal of Analytical Atomic Spectrometry, vol. 31, no. 3, pp. 751-758, 2016.

[112] C. Galimberti, I. Corti, M. Cressoni et al., "Evaluation of mercury, cadmium and lead levels in fish and fishery products imported by air in North Italy from extra-European Union Countries," Food Control, vol. 60, pp. 329-337, 2015.

[113] Y. Pang, Z. Rong, R. Xiao, and S. Wang, "'Turn on' and labelfree core - Shell Ag@SiO2 nanoparticles-based metal-enhanced fluorescent (MEF) aptasensor for Hg2+," Scientific Reports, vol. 5, article 9451, 2015. 
[114] K. Zargoosh and F. F. Babadi, "Highly selective and sensitive optical sensor for determination of $\mathrm{Pb} 2+$ and $\mathrm{Hg} 2+$ ions based on the covalent immobilization of dithizone on agarose membrane," Spectrochimica Acta Part A: Molecular and Biomolecular Spectroscopy, vol. 137, pp. 105-110, 2015.

[115] H. R. Rajabi, M. Shamsipur, M. M. Zahedi, and M. Roushani, "On-line flow injection solid phase extraction using imprinted polymeric nanobeads for the preconcentration and determination of mercury ions," Chemical Engineering Journal, vol. 259, pp. 330-337, 2015.

[116] X. Ding, L. Qu, R. Yang, Y. Zhou, and J. Li, "A highly selective and simple fluorescent sensor for mercury (II) ion detection based on cysteamine-capped CdTe quantum dots synthesized by the reflux method," Luminescence, vol. 30, no. 4, pp. 465-471, 2015.

[117] D. Huang, C. Niu, G. Zeng, X. Wang, and X. Lv, "A highly sensitive protocol for the determination of $\mathrm{Hg} 2+$ in environmental water using time-gated mode," Talanta, vol. 132, pp. 606-612, 2015.

[118] D. Nanda Kumar, A. Rajeshwari, S. A. Alex, N. Chandrasekaran, and A. Mukherjee, "Acetylcholinesterase inhibition-based colorimetric determination of $\mathrm{Hg} 2+$ using unmodified silver nanoparticles," New Journal of Chemistry, vol. 39, no. 2, pp.11721178, 2015.

[119] W. Li, B. Chen, H. Zhang et al., "BSA-stabilized Pt nanozyme for peroxidase mimetics and its application on colorimetric detection of mercury(II) ions," Biosensors and Bioelectronics, vol. 66, pp. 251-258, 2015.

[120] Y. Zhang, H. Jiang, and X. Wang, "Cytidine-stabilized gold nanocluster as a fluorescence turn-on and turn-off probe for dual functional detection of $\mathrm{Ag}+$ and $\mathrm{Hg} 2+$, , Analytica Chimica Acta, vol. 870, no. 1, pp. 1-7, 2015.

[121] J. Jia, H. G. Chen, J. Feng, J. L. Lei, H. Q. Luo, and N. B. Li, "A regenerative ratiometric electrochemical biosensor for selective detecting $\mathrm{Hg} 2+$ based on Y-shaped/hairpin DNA transformation," Analytica Chimica Acta, vol. 908, pp. 95-101, 2016.

[122] Z. Li, S. Xia, J. Wang, C. Bian, and J. Tong, "Determination of trace mercury in water based on N-octylpyridinium ionic liquids preconcentration and stripping voltammetry," Journal of Hazardous Materials, vol. 301, pp. 206-213, 2016.

[123] I. T. Somé, A. K. Sakira, D. Mertens, S. N. Ronkart, and J.M. Kauffmann, "Determination of groundwater mercury (II) content using a disposable gold modified screen printed carbon electrode," Talanta, vol. 152, pp. 335-340, 2016.

[124] A. Zahid, A. Lashin, U. A. Rana et al., "Development of surfactant based electrochemical sensor for the trace level detection of mercury," Electrochimica Acta, vol. 190, pp. 1007-1014, 2016.

[125] M. A. Armas, R. María-Hormigos, A. Cantalapiedra, M. J. Gismera, M. T. Sevilla, and J. R. Procopio, "Multiparametric optimization of a new high-sensitive and disposable mercury (II) electrochemical sensor," Analytica Chimica Acta, vol. 904, pp. 76-82, 2016.

[126] A. Shirzadmehr, A. Afkhami, and T. Madrakian, "A new nano-composite potentiometric sensor containing an $\mathrm{Hg} 2+$-ion imprinted polymer for the trace determination of mercury ions in different matrices," Journal of Molecular Liquids, vol. 204, pp. 227-235, 2015.

[127] E. Xiong, L. Wu, J. Zhou, P. Yu, X. Zhang, and J. Chen, "A ratiometric electrochemical biosensor for sensitive detection of $\mathrm{Hg} 2+$ based on thymine-Hg2+-thymine structure," Analytica Chimica Acta, vol. 853, no. 1, pp. 242-248, 2015.
[128] J. Jing, L. Yu, G. Z. Feng, L. J. Lei, L. H. Qun, and L. N. Bing, "A regenerative electrochemical biosensor for mercury(II) by using the insertion approach and dual-hairpin-based amplification," Journal of Hazardous Materials, vol. 295, pp. 63-69, 2015.

[129] D. M. Chen, Z. F. Gao, J. Jia, N. B. Li, and H. Q. Luo, "A sensitive and selective electrochemical biosensor for detection of mercury(II) ions based on nicking endonuclease-assisted signal amplification," Sensors and Actuators B: Chemical, vol. 210, pp. 290-296, 2015.

[130] M. R. Ganjali, F. Faridbod, N. Davarkhah, S. J. Shahtaheri, and P. Norouzi, "All solid state graphene based potentiometric sensors for monitoring of mercury ions in waste water samples," International Journal of Environmental Research, vol. 9, no. 1, pp. 333-340, 2015.

[131] A. Mao, H. Li, Z. Cai, and X. Hu, "Determination of mercury using a glassy carbon electrode modified with nano $\mathrm{TiO} 2$ and multi-walled carbon nanotubes composites dispersed in a novel cationic surfactant," Journal of Electroanalytical Chemistry, vol. 751, pp. 23-29, 2015.

[132] Y. Liao, Q. Li, N. Wang, and S. Shao, "Development of a new electrochemical sensor for determination of $\mathrm{Hg}$ (II) based on Bis(indolyl)methane/Mesoporous carbon nanofiber/Nafion/ glassy carbon electrode," Sensors and Actuators B: Chemical, vol. 215, pp. 592-597, 2015.

[133] M. H. Mashhadizadeh, S. Ramezani, and M. K. Rofouei, "Development of a novel MWCNTs-triazene-modified carbon paste electrode for potentiometric assessment of $\mathrm{Hg}(\mathrm{II})$ in the aquatic environments," Materials Science and Engineering C: Materials for Biological Applications, vol. 47, pp. 273-280, 2015.

[134] A. Farahi, S. Lahrich, M. Achak, M. Bakasse, and M. A. El Mhammedi, "Effect of $\mathrm{KNO} 3$ to remove silver interferences in the determination of mercury(II): application in milk and breast milk samples," Sensing and Bio-Sensing Research, vol. 4, pp. 90-95, 2015.

[135] A. Farahi, M. Achak, L. ElGaini, S. ElYamani, M. Bakasse, and M. A. ElMhammedi, "Effect of pulse width of square potential to remove silver interference in the determination of mercury(II)," Electroanalysis, vol. 27, no. 8, pp. 1979-1988, 2015.

[136] Y. Yang, M. Kang, S. Fang et al., "Electrochemical biosensor based on three-dimensional reduced graphene oxide and polyaniline nanocomposite for selective detection of mercury ions," Sensors and Actuators B: Chemical, vol. 214, pp. 63-69, 2015.

[137] Y. Lin, Y. Peng, and J. Di, "Electrochemical detection of $\mathrm{Hg}$ (II) ions based on nanoporous gold nanoparticles modified indium tin oxide electrode," Sensors and Actuators B: Chemical, vol. 220, Article ID 18641, pp. 1086-1090, 2015.

[138] S. L. Ting, S. J. Ee, A. Ananthanarayanan, K. C. Leong, and P. Chen, "Graphene quantum dots functionalized gold nanoparticles for sensitive electrochemical detection of heavy metal ions," Electrochimica Acta, vol. 172, pp. 7-11, 2015.

[139] E. Fernández, L. Vidal, D. Martín-Yerga, M. D. C. Blanco, A. Canals, and A. Costa-García, "Screen-printed electrode based electrochemical detector coupled with ionic liquid dispersive liquid-liquid microextraction and microvolume backextraction for determination of mercury in water samples," Talanta, vol. 135, pp. 34-40, 2015.

[140] Z.-M. Dong, X.-M. Qing, and G.-C. Zhao, "Highly sensitive EQCM sensor for mercury determination by coupled stripping voltammetry," International Journal of Electrochemical Science, vol. 10, no. 3, pp. 2602-2612, 2015. 
[141] Y. M. Sabri, K. M. M. Kabir, E. Boom, S. Rosenberg, S. J. Ippolito, and S. K. Bhargava, "Mercury detection in real industrial flue gas using a nanostructured quartz crystal microbalance," Industrial \& Engineering Chemistry Research, vol. 55, no. 28, pp. 76617668, 2016.

[142] K. M. Kabir, Y. M. Sabri, A. E. Kandjani et al., "Mercury sorption and desorption on gold: a comparative analysis of surface acoustic wave and quartz crystal microbalance-based sensors," Langmuir, 2015.

[143] P. Larki, Y. M. Sabri, K. M. M. Kabir, A. Nafady, A. E. Kandjani, and S. K. Bhargava, "Silver/gold core/shell nanowire monolayer on a QCM microsensor for enhanced mercury detection," $R S C$ Advances, vol. 5, no. 112, pp. 92303-92311, 2015.

[144] Z. Guo, B. Chen, Z. Wang, and X. Jiang, "An electrochemiluminescence biosensor for mercury ion detection based on gammapolyglutamic acid-graphene-luminol composite and oligonucleotides," Sensors and Actuators B: Chemical, vol. 209, pp. 579585, 2015.

[145] F. Cai, Q. Zhu, K. Zhao, A. Deng, and J. Li, "Multiple signal amplified electrochemiluminescent immunoassay for $\mathrm{Hg} 2+$ using graphene-coupled quantum dots and gold nanoparticleslabeled horseradish peroxidase," Environmental Science \& Technology, vol. 49, no. 8, pp. 5013-5020, 2015. 

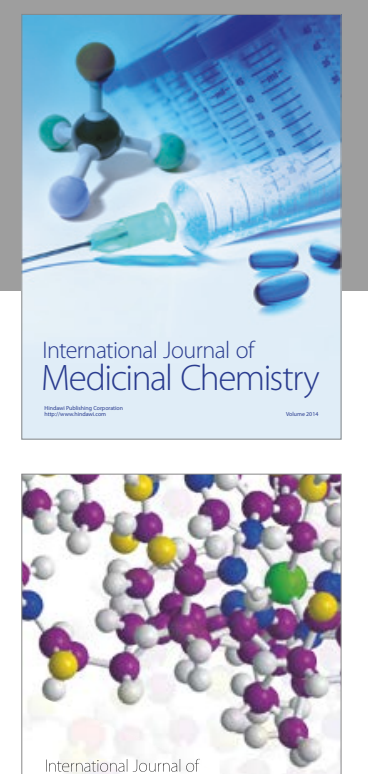

Carbohydrate Chemistry

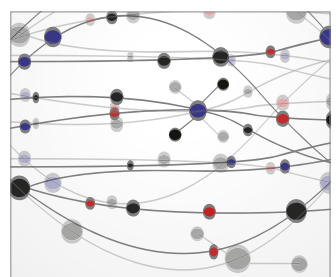

The Scientific World Journal
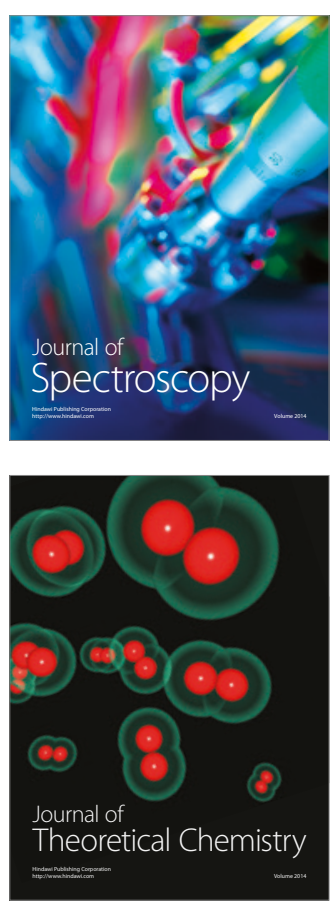
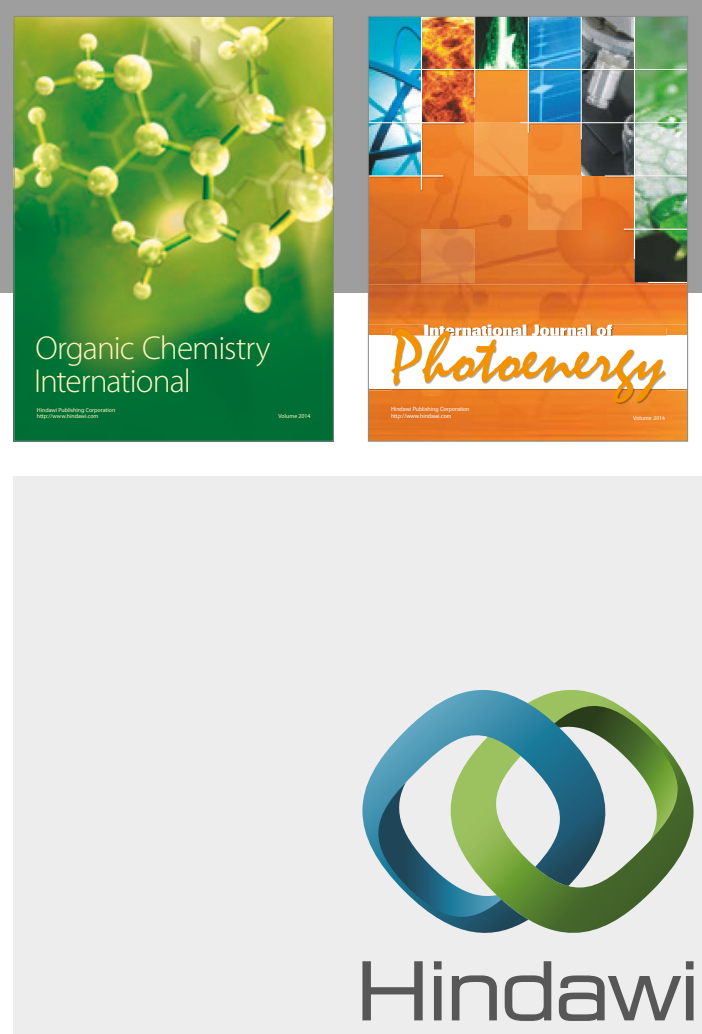

Submit your manuscripts at

https://www.hindawi.com

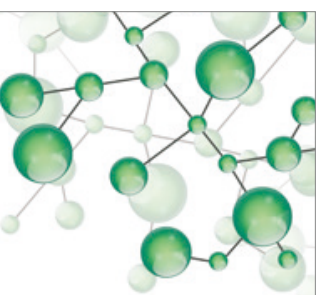

International Journal of

Inorganic Chemistry

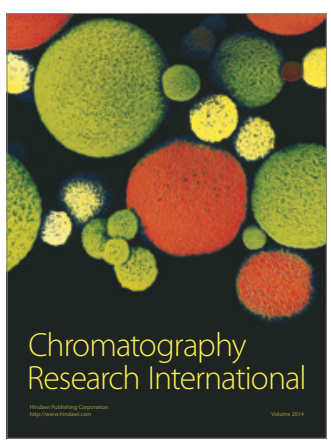

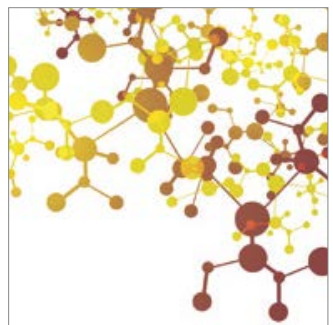

Applied Chemistry
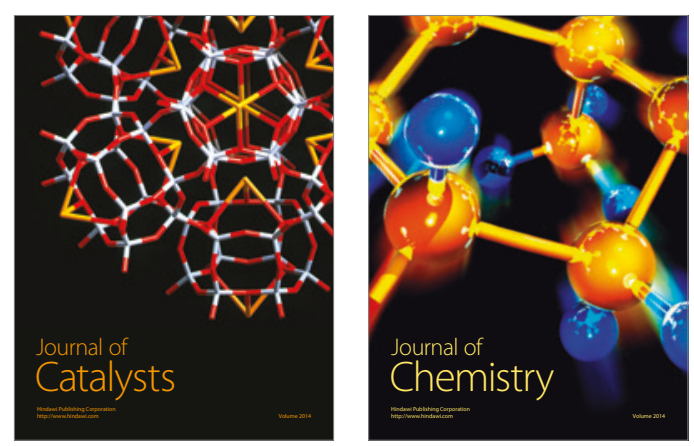
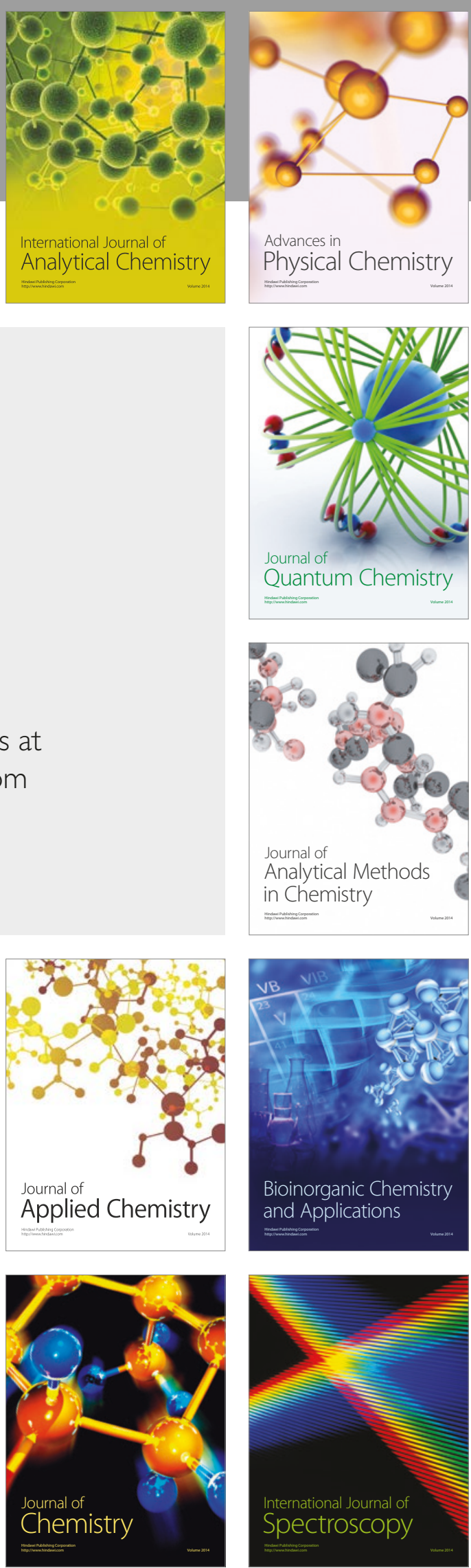